\title{
Manoeuvring between Networks to Lead - A Longitudinal Case Study in the Semiconductor Industry
}

\author{
Gordon Müller-Seitz* and Jörg Sydow
}

Department of Management, Freie Universität Berlin, Boltzmannstr. 20, 14195 Berlin, Germany

* Corresponding author. Tel.: +49 3083856 359; fax: +49 3083856808.

E-mail address: gordon.mueller-seitz@fu-berlin.de

\section{Acknowledgements}

Earlier versions of this paper have been presented at the 2009 EGOS Colloquium in Barcelona, Spain, at the 2009 Academy of Management Meeting in Chicago, USA, as well as in research seminars at the Radboud University Nijmegen (Management \& Technology Department) and University of Tilburg (Department of Organisation Studies), both in the Netherlands. We are grateful for the financial support of the Volkswagen Foundation under grant AZ II/80308 and the German Research Foundation (DFG) under grant MU 3070/1-1, as well as helpful feedback from participants at these venues and, in particular, from Vincent Mangematin. Moreover, we are indebted to the thoughtful guidance of the LRP associate editor Giovanna Padula as well as three anonymous reviewers for their constructive criticism.

Published in: Long Range Planning 45 (2012), pp. 105-135. 


\section{Bibliographical notes}

Dr. Gordon Müller-Seitz is a researcher at the Freie Universität Berlin, School of Business \& Economics. His research focuses upon interorganizational networks, open source software related phenomena, innovative technologies, project management, and professional service firms. His work has been applied at retail corporations and consulting firms and has appeared in Organization, Industry \& Innovation, R\&D Management, and the International Journal of Technology Management. Department of Management, Freie Universität Berlin, Boltzmannstr. 20, 14195 Berlin, Germany. Phone: 49-30-78 546 E-Mail: gordon.muellerseitz@fu-berlin.de

Dr. Jörg Sydow is a Professor of Management at the Freie Universität Berlin, School of Business \& Economics. He was an International Visiting Fellow at the Advanced Institute of Management (AIM) Research in London and is now a Visiting Professor at the Graduate School of Business, University of Strathclyde. He is on the editorial boards of Organization Studies, Organization Science, Business Research, Academy of Management Review and The Scandinavian Journal of Management. For further information visit: http://www.wiwiss.fuberlin.de/institute/management/sydow/.E-mail: joerg.sydow@fu-berlin.de 


\begin{abstract}
How organizations exert leadership in interorganizational, predominantly hierarchical networks is well researched. However, there are also networks that are not hierarchical, but heterarchical in nature, i.e. where no organizational actor formally presides over the other member organizations and where leadership is nevertheless practised and accepted by network members. But how exactly is an organization able to lead under these structural conditions and, in particular, to capitalize - in the leadership process - on its membership in more than one network? Informed by structuration theory, we investigate this practice of 'network manoeuvring', that is, how an organization skilfully takes advantage of the reciprocal influences between two different forms of networks. In particular, we study Intel de facto leading the SEMATECH consortium (i.e. a heterarchical network) and guiding technology development along its supply chain (i.e. a hierarchical network). Network manoeuvring is enabled in this case by two mutually reinforming practices (i.e. roadmapping and roadmap gap filling) centred around a key resource (i.e. a roadmap as an artefact). Based upon our findings, we provide practical guidance and theoretical insights on how and under what circumstances this kind of manoeuvring in and across two (different types of) networks substitutes for formally legitimated leadership.
\end{abstract}




\section{Introduction}

Collaborating on a long-term basis in an interorganizational network of three or more entities is quite common for organizations, in particular in science-based industries like information and communication technology, biotechnology or photonics ${ }^{1}$. Building collaborative networks is motivated by factors such as sharing research and development costs and risks, gaining access to new markets and skills, or speeding up the introduction of new products or processes. Given the prevalence and significance of such networks, it is not surprising that previous research has concentrated upon how organizations are positioned within such networks and, ensuing from this, how they are able to exploit or improve their situation within and across networks ${ }^{2}$. Studies in the tradition of the relational view and literature on alliance portfolios in particular point at the beneficial role of dense relationships ${ }^{3}$.

However, what is less often analyzed is how organizations actually lead such networks comprehended as exerting an influence in order to make things happen, more often than not through the actions of others, in line with one's own objectives that might conflict with other organizations' interests ${ }^{4}$. These studies concentrate upon hierarchical networks that dispose of a formally legitimated lead organization directly or indirectly controlling the respective network activities. Although not explicitly targeting how leadership is exerted, the studies from a relational view help us to comprehend how managing network relationships can make a difference concerning knowledge sharing. Thereby, the leading organizations have been labelled, among others, hub firms, network orchestrators or strategic centres ${ }^{5}$. For instance, Lorenzoni and Baden-Fuller analyze how hierarchical networks surrounding companies like Apple, Nintendo, Sun or Toyota are successfully led by strategic centres. Flanking these studies concentrating upon single networks, recent research on alliance portfolios has added a new level of analysis and advanced our understanding concerning a focal organization's embeddedness into multiple interorganizational constellations and the interdependencies between them ${ }^{6}$. 
Exhibit 1 about here

These studies, however, do not explicitly focus upon leadership practices in networks. In particular, those of the latter kind fail to do so, because portfolio approaches usually target only dyads and lack longitudinal and micro-level insights ${ }^{7}$. What is more, literature on interorganizational networks has paid little attention to leadership in networks that are not hierarchical, but heterarchical in nature, i.e. consisting of more or less equal partners that do not formally dispose of a leading actor. Despite extensive research on heterarchical structures in other than (inter) organizational settings (e.g. interpersonal networks concerning the development of open source software or multinational corporations) and their relevance and ubiquity in diverse fields, previous studies have seldom paid attention to the question of how such 'leaderless networks' can be led by one of their members ${ }^{8}$. This is unfortunate, since leadership in the sense of making things happen, often through the actions of others, clearly exists in such networks as well. Take for example production cooperatives in the wine industry or research and development consortia, including SEMATECH, in the semiconductor manufacturing industry. ${ }^{9}$ Against this background, this study asks: How and under what circumstances can an organization lead a heterarchical network?

In this article we offer an answer to this question by studying the semiconductor industry, in which the SEMATECH consortium is positioned: a heterarchical network led by Intel. Intel achieves this factual leadership by network manoeuvring, a term we introduce to denote taking advantage of being engaged in different networks (here, more precisely, even two different types of networks: SEMATECH as a heterarchical network and parts of Intel's supply chain conceived as a hierarchical network), whereby it is possible to capitalize skilfully on an imbalance between these networks in the absence of hierarchical fiat. According to our study, Intel achieves this by a 
set of diverse leadership practices that make use of and, at the same time, influence the International Technology Roadmap for Semiconductors (ITRS) - an industry-wide projection of future technological milestones. As we will show, both networks are affected by the ITRS and Intel is able to influence what happens in both networks: in SEMATECH by filling gaps of the ITRS in the course of leading its supply chain, effectively leveraging its impact by intertwining the activities of both networks, that is, network manoeuvring. We utilize structuration theory ${ }^{10}$ to analyze this phenomenon, as it offers a framework that allows the incorporation of a multilevel and multidimensional analysis of network manoeuvring as a leadership practice without neglecting structural aspects. Moreover, structuration theory enables us to incorporate instability and conflicts in the course of network manoeuvring, rejecting the idea of stability, in particular in heterarchical networks.

For practitioners, this study offers insights into how leadership in a heterarchical network can be achieved by means of manoeuvring skilfully between different (types of) networks by pointing at the two intertwined leadership practices each consisting of a subset of micropractices. Furthermore, it points at the importance of venturing beyond more macro-oriented portfolio approaches as well as beyond isolated accounts of single networks. For academics, our concept of manoeuvring is interesting as it expands - in line with Gulati's call - the scope of present research on interorganizational networks beyond single networks. In addition, a structuration approach allows for the conception of leadership in heterarchical networks as structured and structuring practices, and permits us to venture beyond explanations focusing upon isolated events or accounts of reputation or financial power - predominantly related to hierarchical networks - that could not, alone, explain Intel’s influence.

In the remainder of the paper we develop and position our structurationist conception of network manoeuvring and contrast hierarchical and heterarchical networks to introduce the two types of networks within which Intel operates. Next, we explain how we collected and analysed 
our data. Subsequently, we set forth how network manoeuvring in and across two types of networks unfolds by indicating a subset of relevant practices that elucidate how Intel is able to exert leadership by means of making use of the ITRS. We conclude by discussing implications of network manoeuvring in managerial practice and sketch options for future network research.

\section{Conceptual and theoretical background}

Leadership in networks has been addressed from a variety of disciplines, focusing not only on interpersonal and intraorganizational networks, but also on interorganizational networks, from open source software development to joint ventures and strategic alliance systems ${ }^{11}$. Given our focus on network manoeuvring as a leadership practice by a single organization, we position our study in the rich tradition of research on interorganizational alliances and networks. Before we identify issues that still need further exploration, we offer a brief definition of the key concepts of this study, that is, contrasting hierarchical and heterarchical interorganizational networks and the leadership therein before we introduce our structurationist perspective on leadership practices.

\section{Leadership in interorganizational networks}

The kind of leadership that interests us in this paper occurs in interorganizational networks, conceived as a social system in which the activities of at least three formally independent legal entities are coordinated in time-space, i.e. there is some reflexively agreed upon inter-firm division of labour and cooperation among the network members ${ }^{12}$. This definition presents the interorganizational network as a form of governance rather than offering a network analytic perspective. As shown in Table 1 with regard to their different features, this governance can take

on two distinct forms: hierarchical and heterarchical, which are characterized by distinct 
properties (see Table 1) but obviously overlap in reality and, therefore, should be conceived as extreme points of a bipolar continuum.

Table 1 about here

Accounts of hierarchical networks point at an officially / formally legitimated leadership exerting organization. The lead organization is enduringly able to control the network-wide activities due to having the respective authority-based backing. Previous research has labelled such organizations, among other terms, as network orchestrators, strategic centres or hub firms. This research can be traced back to the discussion of strategic networks and has been revived under the rubric of supply chains and supply networks ${ }^{13}$. One of the most influential works in this respect was that of Jarillo, who explicitly assumes a hierarchical structure within the respective network that is coordinated by a hub firm. For empirical evidence, these studies often refer to large multinational corporations and parts of their supply chain, or to Japanese keiretsu. In particular Dyer and colleagues, in promoting the relational view, hereby advance our understanding of how to organize such network forms. For the case of Toyota they show how establishing strong ties serves to lower transaction costs while still being able to improve the knowledge specialization of and knowledge transfer among partners.

Research on leadership in heterarchical interorganizational networks is comparatively scarce and concentrates upon networks that lack formal central coordination, where decisions are officially made in consensus. Usually these networks exhibit some efforts of collective strategizing. Thereby actors attempt to assume a leading role in a concerted effort concerning the activities that are of relevance for them. However, due to a lack of hierarchical fiat and a correspondingly low degree of power differentials, their activities - more than in hierarchical networks - need to be accepted by the fellow network members. This also implies that leadership 
in this type of network is particularly fragile and not necessarily enduring, rather temporary in nature $^{14}$. Although the heterarchical character of interorganizational networks is hardly investigated, relevant issues have been addressed in related research on similar phenomena. For instance, studies devoted to network and alliance evolution offer fruitful insights into how networks of interorganizational relationships are formed. Representative of this stream of research are, for instance, studies by Rosenkopf and Tushman that have advanced our understanding of how networks and technology coevolve, focusing, among other things, upon the role of cooperative technical organizations that resemble our conception of heterarchical networks ${ }^{15}$. In a similar vein, studies on research and development consortia have shown that cooperation also relies upon informal coordination mechanisms to reach consensus (e.g. research emanating from the Minnesota innovation studies ${ }^{16}$ ). Furthermore, previous studies on regional networks or industrial clusters - for instance in Silicon Valley or Italian districts like Emilia Romagna - illuminate how organizations coevolve, although their unit of analysis is not usually a 'whole network' or 'explicit constellations' within these clusters ${ }^{17}$, but different complex, and often intransparent overlapping interorganizational relationships including dyads. Although these studies have advanced our understanding by directing our attention towards the consensus-based nature of these constellations, leadership issues are usually not explicitly addressed, although it is acknowledged that such networks are by no means a 'leadership free vacuum' or an egalitarian arena. Previous research by, among others, Huxham and Vangen, as well as Boari and Lipparini indicates that it seems rather more adequate to perceive heterarchical networks as a complex phenomenon whose governance remains unclear.

Relating to these latter studies, we conceive leadership in interorganizational networks as influencing of the network activities by a single or by multiple organizations, whereby the respective organization(s) is or are "making things happen” (often through the actions of others as well). These activities are commonly perceived and accepted by the other network participants $^{18}$. Though not geared towards the theme of leadership, but clearly set against the 
backdrop thereof, illustrative evidence stems in this regard from supplier networks. Dyer and colleagues, for instance, identify mechanisms by which knowledge transfer was improved at Toyota via relation-specific capabilities and investing in the suppliers for joint purposes (e.g. by transferring personnel or investing capital).

A specific leadership practice is network manoeuvring which is based upon the lead organizations capability to exploit its membership in more than one network. This capability can rest upon superior financial endowments, dependence on particular goods or services, organizational reputation and/or a network position offering access to superior knowledge ${ }^{19}$. Herein, parallels can be drawn to the well established literature on alliance portfolios. Although leadership is usually not studied, it is implied and the respective studies do inform us about the interdependencies among different alliances concerning potential benefits regarding learning and communication flows. However, it is worth noting that network manoeuvring and leadership in general do not necessarily assume an impact due to sheer dominance, e.g. in terms of market power, although this often occurs simultaneously. As we will illustrate empirically for the case of network manoeuvring between two different types of networks, leadership can also express itself in more subtle ways, as acting 'behind the scenes' to achieve desired outcomes or as enrolling other network members in line with one’s own objectives - be it by openly soliciting for the legitimacy of one's own actions or rather in a 'disguised form' (i.e. the other members are not fully aware of acting in line with the other network member's objectives, cf. also Exhibit 1). In any of these cases, leadership in interorganizational networks differs from leadership within organizations, since networks lack the possibility of directing the other via hierarchical fiat. In turn, this means that leadership in such networks always implies orienting, guiding and coordinating the activities of more or less independent and often similarly powerful organizations. This also implies that organizations, whatever the power differentials, influence each other reciprocally. 
Table 2 about here

Table 2 offers an overview of relevant studies addressing leadership issues similar to our conception, although the terms used differ. Typically, these studies discuss hierarchical network settings where a powerful organization 'orchestrates' a number of network partners. For instance, Hinterhuber refers to orchestration as aligning the network partners' competences to achieve superior performance while reverting to empirical evidence from the networks of Monsanto and DuPont. In a similar vein, Hung refers to mobilizing networks and shows how three Taiwanese computer firms - Acer, FIC and Mitac - achieve advantages over their competitors. The case of Mitac is particularly interesting for us, as Hung labels Mitac an ambidextrous player that is capable of skilfully using its relationships to other firms and networks. However, exactly how Mitac achieves this across networks is not set out in detail.

Another prominent stream of research addresses how single organizations can govern networks. Common themes addressed here are issues of trust, risk and control. The scope of Nosella and Petroni's research is probably the closest of the studies mentioned above. This is not only because they explicitly refer to the leadership of a single organization in different networks, but as they also offer closer insights into the way the four different networks overlap and how the lead firm is able to make use of synergies from being active in different networks. However, the study is not based upon a longitudinal analysis, which is why the dynamics of interorganizational leadership were not considered, an aspect the authors point out as interesting to study in future research.

To sum up: in the literature on leadership in interorganizational networks, two issues that are relevant for the purposes of this study remain rather unexplored so far, but are essential for the concept and analysis of network manoeuvring when understood as a leadership practice that 
makes use of membership in more than one (type of) network. First, it remains by and large unexplored how organizations exert leadership in heterarchical interorganizational networks. Second, and even more important for the notion of network manoeuvring, studies either adopt a more micro perspective when they concentrate on an isolated interorganizational network or employ a more macro-oriented lens when they take a portfolio approach ${ }^{20}$. Network manoeuvring as defined above is positioned in between these two perspectives or levels. Hence, we respond on the one hand to Nosella and Petroni, who point to the need to analyse leadership dynamics (here: network manoeuvring as a practice) and we also offer a response to Gulati’s call to venture beyond analysing single networks as a unit of analysis by taking the activities between networks into account.

Finally, although in previous research some activities of organizations in networks have already been termed manoeuvring, the respective usage does not capture the essence of the phenomenon we are targeting, as these studies either make only fleeting reference to the term or do not consider interactions between or shifts across interorganizational networks ${ }^{21}$. Therefore we introduce network manoeuvring for the purposes of this study as taking advantage of being engaged in two different types of entities (here: networks), whereby it is possible to capitalize skilfully on a difference between these systems in the absence of hierarchical fiat. Manoeuvring in and across networks can take manifold forms and may be based not only on these differences, but also on superior financial assets or a well-established reputation. In more general terms, the respective organization is able to frame the conditions relevant for the respective network's activities by facilitating, inhibiting or maintaining relationships and/or information flows, thereby effectively leveraging its impact by intertwining activities of different networks. 


\section{A structuration perspective on leadership practices}

Tracking network manoeuvring requires a theoretical perspective that allows us to capture how such leadership is actually enacted over time, which is why a process or practice perspective is necessary. This approach is in line with previous research that conceives of leadership not only as dynamic, but - in organizations and even more so in interorganizational networks - also as a complex, contested and diffuse phenomenon that cannot be captured at one point in time ${ }^{22}$. Structuration theory allows us to capture practices and how they are enacted in face of existing (here: heterarchical and hierarchical network) structures and the way that they contribute to the reproduction or transformation of these very structures over time; at the same time, allowing a multilevel analysis (here: the organizational and network levels).

Figure 1 about here

Perhaps even more importantly, structuration theory requires a multidimensional analysis. While most theories of networks deal with issues such as economics, power, sense-making, or the legitimacy in and of interorganizational networks, structuration theory follows the theorem of the duality of structure (cf. Figure 1), which emphasizes not only the recursive interplay between action and structure, but analytically differentiates the practically interrelated dimensions of signification, legitimation, and domination that address these issues. Actors refer to these structures - with regard to all three dimensions - on the level of the network as well as on other levels of analysis (e.g. the single organization) in their social practices, and (re)produce or transform them (and themselves) recursively.

Moreover, following Giddens, structuration theory serves as a sensitizing device in its function as a grand theory, which can be augmented by diverse theoretical approaches relevant to the respective phenomenon at stake (in our case: leadership in different organizational forms). 
Applying structuration theory to our context requires an analysis of leadership practices ${ }^{23}$ whereby some network members more than others actually 'make things happen', first with regard to how they refer in their communications - via interpretive schemes - to rules of signification (e.g. ascribing relevance to a technological option in face-to-face communications). These rules - as structures - either prevail in the particular organization leading the network, in the interorganizational network, or in the industry in which the organizations and networks are acting. Thereby, they either (re)produce or transform these structures. The same can be said with respect to rules of legitimation: agents draw - by the use of norms - upon this kind of structure in the course of sanctioning behaviour (e.g. obtaining access to interorganizational resources related to a specific technology). With respect to resources of domination, agents refer to this third type of structure via facilities to powerfully intervene in ongoing interactions (e.g. by means of channelling financial resources or expertise to specific technological options). While this latter type of intervention seems to be particularly important for making things happen powerfully in networks, the duality of structure points to the fact that effective leadership interventions depend upon the subtle interplay of all three dimensions, i.e. that powerful interventions make sense to those 'led' and are hence considered as legitimate.

The major advantage of structuration theory, beyond its multilevel and multidimensional approach, is that it helps to analyze interorganizational networks as recursively reproduced social practices and, thereby, focuses on the dynamics and dialectics inherent in this organizational form. For instance, a leadership practice that is not considered useful and legitimate by network participants might be questioned and trigger changes in the network constellation with regard to the leading organization, and can thus be captured adequately from a structuration perspective. Thus, not only changes in leadership over time can be analyzed, but contradictions can also be taken into account, e.g. de facto leading a network informally while it remains symbolically heterarchical in nature. Due to differences in abilities to revert to resources of domination and rules of signification and legitimation that cushion them, this holds true in 
hierarchical networks more than in organizational hierarchies, and in heterarchical more than in hierarchical networks. In this respect too, structuration theory, which has already been applied to the analysis of different practices in organizations (e.g. by Denis and colleagues as well as Jarzabkowski), can be used to overcome many deficiencies found in the present analyses of interorganizational networks.

\section{Research setting and methodology}

The overall research setting is the semiconductor industry, which was chosen as a research object due to the relevance of interorganizational networks for this industry ${ }^{24}$. Recent developments serve to underscore the relevance of network arrangements to be found in this industry: current discussions on the part of U.S. automotive suppliers regarding the potential installation of a consortium modelled on SEMATECH are being held in an attempt to save the U.S. automotive supplier industry ${ }^{25}$.

Within the semiconductor industry, our analysis concentrates upon Intel (short for Integrated Electronics Corporation), the world's largest semiconductor company with an overall market share in the semiconductor industry of about $13 \%$. The company's concentration is on the microprocessor business, where its market share is unparalleled, currently nearly $80 \%{ }^{26}$. In keeping with the objective of this paper, in order to analyze the activities of this network actor it is also important to turn to its membership in two different (types of) networks, SEMATECH, and the company's impact on parts of its own supply chain regarding a specific technology.

SEMATECH was established in 1987 as a nationally operating, pre-competitive, non-profit research and development network. According to Browning and Shetler, it needed consensus on its structure from all members and "freedom from internal domination" by a single organization. Although the term heterarchic network is not used officially by the consortium, it corresponds to our conception thereof, as the independent member organizations are linked to one another by 
being not only enrolled at SEMATECH contractually but by interacting laterally, not least by utilizing the same pre-competitive testing facilities. The heterarchic character is also embodied in the 'one member one vote rule, ${ }^{27}$. Therefore, decisions and allocations of the annual budget of approximately U.S. \$ 140 million are consensual or, in the case of disagreements, favours are returned. The consortium is led by the so-called Executive Management Team (which consists of the Chief Executive Officer and President as well as three Vice Presidents) and cooperates closely with two other bodies, the Executive Steering Council on the overall directions of SEMATECH and the Board of Directors. Each of these three bodies is staffed by its member companies, who decide jointly about the annual budget. The diversity of activities into which the funding is channelled is predominantly ensured on an operative basis by around 100 assignees from all the member companies, who work on specific assignments that last for two to three years. The initial publicly funded purpose of SEMATECH was to regain the worldwide leadership position of U.S. chip manufacturers, who had lost market shares to their Japanese competitors in the 1980s. Public funding, however, ceased in 1996, when the U.S. semiconductor manufacturers regained their leading role on the worldwide market. From that time onwards, funding has been ensured entirely by member contributions or contract-based research. By the late 1990s, the consortium had also opened up to foreign companies, becoming known as International SEMATECH. Currently, the member organizations from the U.S. and South-East Asia are associated with one another by coordination of their joint research and development activities within SEMATECH while being formally enrolled at SEMATECH via member fees. Thirteen member organizations are private firms and the consortium includes one research institute. As the latter is a public institution, SEMATECH now (again) receives public funding. Taken together, these organizations dominate the semiconductor industry landscape, as its members represent around $50 \%$ of the worldwide production output in this sector.

Intel's influence within SEMATECH cannot be explained by financial data; Intel is not the most financially potent actor, as there are several other big corporations involved, e.g. IBM, 
Hewlett Packard or Samsung. As previous studies like that of Browning and Shetler as well as our interviewees confirmed, no formally legitimated leadership-exerting organization presides over the consortium. In addition, the members pursue different technological options like extreme ultraviolet lithography (EUV; e.g. Intel) and e-beam projection lithography (e.g. IBM), which is why the organizations are attempting to exert an influence concerning a limited range of network related activities, making SEMATECH even less centralized and network leadership potentially contested. It is striking that network leadership does not only vary with regard to technological options, but also over time. For instance, IBM was formerly the leading actor, whereby this changed increasingly to Intel over time. Furthermore, there was a transition period in between when various actors vied to lead the consortium's activities. This held particularly true when no consensus was achieved regarding the next generation lithography sought for in the 1990s (which led in the end to Intel's rise as the leading organization; cf. Exhibit 1). Hence, we consider SEMATECH to be a heterarchical network in which partners are linked to one another on the basis of formal membership as well as by joint research and development activities that are repeatedly (re)negotiated, i.e. represent a form of collective strategizing as no member presides over the network. Moreover, the activities of SEMATECH tend to be, at least officially, taken in consensus among equal partners, not least to the 'one member one vote' rule.

Our research setting also embraces companies of Intel's supply chain with regard to semiconductor manufacturing system technologies (cf. Figure 2). Although Intel is inevitably involved in a number of interorganizational constellations, including a variety of supply chains when it comes to differing technological options or parts of microchips, the part of its supply chain we chose (i.e. the specific companies presented in the following) were labelled by interviewees as a single chain with regard to a specific technological option, EUV. 
Figure 2 about here

While Intel is not only by far in terms of revenues, employees etc. the most powerful firm of this supply chain, it is also acknowledged to be the key account company of the respective suppliers, creating a de facto dependence upon Intel, making this network highly centralized around Intel as the lead organization. What is more, Intel's impact covers most almost all areas of the EUV related activities enduringly, which is why we deem it adequate to maintain that this part of the supply chain resembles a hierarchical network. We restrict our analysis to those companies consistently mentioned by interviewees as the most important to Intel in this regard, namely NaWoTec and Media Lario Technologies. NaWoTec (short for NAno WOrld TEChnologies) concentrates upon the development of mask repair systems, and since 2005 has been part of Carl Zeiss SMT AG, a German manufacturer of optical systems. Media Lario Technologies is one level below NaWoTec in the supply chain. The Italian company produces optical components that represent a critical component for NaWoTec in turn.

Since we employ structuration theory to analyze leadership practices, we adopt an interpretative research methodology ${ }^{28}$ that allows us to capture the social practices that are at the centre of any structurationist inquiry. Such methodology is, moreover, most appropriate for exploring a phenomenon that is in need of further research. A longitudinal in-depth case study approach was chosen, as this allows us to generate novel insights concerning how leadership is enacted over time.

Our data collection started in 2003 and, as part of an ongoing study of the way in which complex system technologies are extended and created by interorganizational networks, continued until October 2010. Apart from an initial data collection from secondary sources in the run-up to the project (e.g. non-scholarly publications), for triangulation purposes we utilized 
archival data in order to reconstruct activities at SEMATECH and in the supply chain (e.g. publicly available brochures), 83 semi-structured interviews (on average: 60-90 minutes) as relevant sources for comprehending the activities within SEMATECH and the supply chain, as well as three panels consisting of five different experts, which have been held on an annual basis since 2007 in order to deepen our understanding of the semiconductor industry in general.

In the course of data analysis we made use of a case study database to heighten reliability, comprising 150 pages of field notes, 1,493 pages of interview transcripts, and roughly triple the amount of archival data. We condensed these empirical data with the help of atlas.ti, software for encoding and analyzing qualitative data. Hereby, we constructed data-derived categories that were refined throughout the course of our analysis to researcher-induced (i.e. theoretical) categories, and grouped them hierarchically. For construct validity purposes, the analytical themes were reviewed by key informants in the course of re-entering the field parallel to the three stages. By means of continuing to conduct focused interviews throughout the data analysis phase, ambiguities in our comprehension of roadmapping and roadmap gap filling were resolved. We only present those findings where consensus was reached between our interpretations and the perspectives of the respondents (further details about our method can be found in the Appendix).

\section{Enacting network leadership by influencing roadmaps}

Drawing from our empirical data, we present the enactment of leadership in the heterarchical and hierarchical networks as being constituted by a set of social practices significantly influenced but not entirely determined - by Intel, and formulate propositions to condense the findings that advance our understanding of network manoeuvring as a particular leadership practice. Focusing upon practices is in line with recently renewed calls by Jarzabkowski and others for more practice-based theorizing, usefully grounded in structuration theory. We identify two leadership practices that deserve special attention in connection with network manoeuvring in and across 
the two types of networks: roadmapping as a form of agenda building, as well as roadmap gap filling. Each leadership practice consists of a set of micro-practices that are not mutually exclusive but still distinct from each other, making up the respective practice which they constitute (Figure 3).

The first practice, roadmapping, represents an industry-wide effort to (re)produce an overall orientation for the industry's product and technology development efforts by means of the socalled International Technology Roadmap for Semiconductors, in short ITRS ${ }^{29}$. This practice is particularly related to SEMATECH, i.e. how leadership is exerted by Intel within SEMATECH as a heterarchical network.

Figure 3 about here

Apart from this, Intel's impact can also be perceived in a very tangible fashion in the hierarchical network, that is, in the course of investing large sums into critical organizations along parts of its supply chain. This second practice was perceived to be the most critical practice according to our interviewees and we have termed it roadmap gap filling, adopted in vivo from our interviews.

These two practices mutually inform each other. This is worth noting (see again Figure 3), as it allows Intel to strengthen its influence in both (types of) networks. Intel plays a critical role in the formulation and execution of both networks' agendas as well as in the accompanying pursuit of technological options and, even more importantly, in the network manoeuvring not only within but also across both (types of) networks. 


\section{Roadmapping as a heterarchical network leadership practice}

The continuation of the cooperation among SEMATECH members is ensured by a variety of activities, among them the issuing of an industry-wide agenda, the ITRS, as well as a number of workshops and conferences. As no company is committed to all the fields that SEMATECH is active in, no one aspires to a leading position in all fields. Nevertheless, as we will set out subsequently, Intel is able to manoeuvre its impact regarding those technological options which it favours.

For the semiconductor industry, so-called technological roadmaps are an important technique by which to foster the long-term planning of technological paths or trajectories. Often, these technological roadmaps are not only documented in writing, but contain graphical elements for the exploration and communication of the relationships between evolving and developing products and technologies - and markets - over time. Our case confirms the centrality of roadmaps in these coordinative respects; the ITRS is a decisive tool, as it is issued by a SEMATECH-affiliated organization. Furthermore, this roadmap is commonly considered to be the most important one of the semiconductor industry. Hence, it is not surprising that our interviewees also consistently referred to the ITRS as the roadmap in the industry; it has emerged as a practice for building a collaborative agenda, originally on a national level, and since 1999 on a global level. The ITRS represents a practice insofar as it is regularly updated, usually every two years, with a few official updates in between. It is the coordinative process, "it is 'roadmapping' rather than 'the roadmap' that generates value” ${ }^{30}$. Bearing these notions in mind, it seems plausible to argue that the ITRS serves as a coordinating device for the semiconductor industry as a whole:

"The objective of the ITRS is to ensure cost-effective advancements in the performance of the integrated circuit and the products that employ such devices, thereby continuing the health and success of this industry [...] joining with other strategic roadmapping efforts [...] so the Roadmap effort comprehends the spectrum of needs for basic research capabilities and product potentials. „31 
For this paper it is worth noting that most interviewees refer to the ITRS as a jointly produced artefact that is not dominated by selected organizations, an aspect that is also stressed in the official proclamations of the ITRS. However, some companies - not only Intel, but as we will show predominantly Intel - are more equal than others. In order to pursue its own corporate objectives, and maintain a leadership position within SEMATECH and beyond, our interviewees consistently and regardless of their affiliation aired the opinion that Intel attempts to exert an enduring influence upon the ITRS, by nature in particular with regard to those technological options it favours. In this regard we identified a set of three key micro-practices that in effect contribute substantially to roadmapping - politicking, partnering and consensus-building - and which we will introduce illustratively against the backdrop of the three dimensions of signification, domination and legitimation.

Figure 4 about here

As Intel cannot directly determine the ITRS, it attempts to exert influence by more or less subtly shaping the overall rules of signification and legitimation involved in roadmap creation and alteration, and by coordinating the usages of resources (see Figure 4). Bearing this in mind and focussing on network leadership - via roadmapping as a social practice of constructing an industry-wide orientation - the ITRS can be interpreted in terms of rules of signification in the following way: the relevant actors of the semiconductor industry relate their activities to the ITRS via sense-making activities, which is why they "watch out for homogeneity" as one interviewee put it, an aspect Intel attempts to influence by politicking. This practice serves to influence the way actors assess technological options found in the ITRS in favour of those options Intel pursues. Reverting to our observations in particular when visiting conferences, Intel tries to gain momentum for its technological options like EUV by disseminating official 
information in the form of press releases immediately before or in the course of these venues or keynote presentations. Circulating this information represents an "opportunistic instrument" (I21) as Intel is aware of attracting the attention of fellow network and industry members. These official announcements are flanked, according to our participation at such venues, by a massive presence of Intel employees at these locales. Checking rooster listings, Intel representatives frequently compose the majority of attendees per organization. This finding is noteworthy insofar as we are able to observe that the "carefully placed clues" of announcements as one interviewee put it (I-92), will be substantiated and supported by "hallway conversations” (I-32), whereby Intel representatives reinforce the messages communicated officially in the course of coffee breaks or in meeting rooms attached to the main halls.

As the ITRS represents the aggregated general assumptions and viewpoints of the industry collected, compiled, extrapolated and adjusted by and to the members of SEMATECH - this practice is very effective. The reason is that those technological options that are referred to in the ITRS are likely to attract more resources than alternative technological options. Hence, offering an orientation by politicking represents a way of exerting leadership indirectly by trying to influence the content - and the sense-making of the content - of the ITRS with regard to technological options like EUV, i.e. not to the whole ITRS.

A pooling or re-pooling of resources can be understood, from a structuration perspective at least, as (re-)configuring structure on the social dimension of domination, on the basis of which power can be and actually is exercised in day-to-day interactions. This can be illustrated by the practice of partnering, understood here as selectively engaging with organizations to gain momentum for one's own corporate objectives. This practice ensues from utilizing the ITRS as a reference basis when deciding to cooperate within SEMATECH and beyond to pursue joint technological options. As pointed out for the case of the EUV LLC consortium (cf. Exhibit 1), partnering with fellow SEMATECH members and other organizations from the semiconductor 
industry served to prove the viability of EUV when no consensus was reached among SEMATECH members. However, proving the viability of EUV made EUV the favoured technological option on the ITRS, leading to massive financial resources being channelled into EUV.

This powerful intervention is also closely intertwined with the legitimation of Intel's leadership activities ensuing from the ITRS. Due to the fact that the ITRS signifies what is worth pursuing, it legitimizes the resources that are mobilized for developing one particular technological option. To put it differently: it is considered as legitimate in the semiconductor industry to relate to the ITRS in order to label a technological option as being viable or preferable, even if some actors like Intel have influenced its prioritization to a greater extent than other organizations. Legitimation of the ITRS is even ensured by the fact that it is laid out by all relevant actors of the industry, in particular the big chip manufacturers like Intel, Samsung or Motorola. In this connection, Intel pays particular attention to consensus-building. This micropractice is particularly powerful if employed successfully, as our interviewees confirmed consistently that its impact is augmented due to the assumed impartiality of the roadmap. For instance, when visiting a large scale SEMATECH hosted conference, a senior member of the consortium who is an Intel assignee to SEMATECH presented the results of a survey that was distributed among all organizations concerning the viability of the technological options SEMATECH and its members are likely to pursue at the end of an exclusive dinner on the final evening of the venue. In this connection, it was striking that not all results were interpreted in line with what the presenter announced, as several attendees started to grumble at some interpretations provided that they did not share. Asked about their opinion in this informal setting, an attendee aired that it is "impressive how the survey results are interpreted to foster EUV”, i.e. the technological option, among others, which Intel favours and accordingly ought to be pursued by SEMATECH. As a result, the pooling of resources and lending of significance and 
legitimation fosters the overarching objectives of the roadmap, as well as Intel's own corporate goals.

\section{Roadmap gap filling as a hierarchical network leadership practice}

One important practice for Intel that is directly related to the practice of roadmapping is roadmap gap filling. This terminus can be traced back to Intel's engagement as a technology and market leader in the semiconductor industry, which repeatedly supports critical suppliers to ensure operations along its own (as well as SEMATECH's) supply chain with regard to those technological options that it favours. In what follows we illustrate a set of three key micropractices, identified throughout our analysis, which constitute roadmap gap filling: financing, providing technical expertise and signalling.

Roadmap gap filling, studied here as a leadership practice, relates to specific gaps detected in the ITRS and qualified as 'critical' for the development of the complex system manufacturing technology. Intel Capital, Intel's corporate venture capital entity, plays a central role in the subset of network organizations that 'motivates' the specific supplier (or sometimes subsuppliers) to undertake the risky endeavour of concentrating on activities to produce a particular technological solution, i.e. one which fills the respective gap. For instance, both NaWoTec and Media Lario Technologies have been the target of Intel Capital's investments, as they are indeed critical members of Intel's supply chain regarding EUV. In both cases, financial support was granted by Intel Capital and other venture capital firms were indirectly motivated and directly mobilized to follow suit. Hereby, it was possible to fill the roadmap gaps of Intel's own roadmap, which is informed by and aligned with the ITRS. By supporting suppliers to fill the roadmap gaps, Intel affects the (re)production of these practices in turn. Although Intel Capital closely collaborates with other actors from the venture capital industry in most cases of roadmap 
gap filling, our interview partners ascribe a major role to Intel Capital in supporting the supplier organizations.

The basic principle inscribed in the ITRS is still Moore's law ${ }^{32}$, which pinpoints the doubling of transistors on microchips every two years under conditions of stable costs. In order to fulfil this so-called 'law' in the future, there is a widely shared need for a new technology that succeeds in manufacturing microchips by means of post-optical lithography. At the moment, EUV is considered the most likely candidate for this system technology. Since the system technology is too complex and based on too many diverse bodies of knowledge to be developed by a single company, the industry is looking for coordinated activities to solve the massive coordination problem involved in producing a next-generation technology for chip manufacturing. Intel is ascribed and actively takes up a 'guiding function' for the whole industry in this endeavour for two reasons. First, investments by Intel via Intel Capital are commonly perceived as a strong signal that the respective potential deal - and technology - might be worth pursuing. Second, Intel's venture capital arm operates as a separate entity that disposes of a large amount of financial resources from which Intel can draw in order to exert power.

Figure 5 about here

The different aspects of this crucial leadership practice can be highlighted through the lens of structuration theory as shown in Figure 5. The rules of signification are identifiable concerning the practice of signalling, comprehended here as directing the attention of SEMATECH and industry members towards Intel's, or rather, Intel Capital's activities along its supply chain. Thus when industry actors relate their activities to Intel's roadmap gap filling, they attach importance to Intel's activities. Moreover, the targets of Intel's investments (e.g. NaWoTec or Media Lario 
Technologies) are also aware of signalling. This is highlighted by the former top manager of Media Lario Technologies, who put it succinctly as follows:

"[On the one hand,] Intel Capital itself was as important as any other VC [venture capitalist]. But on the other hand, with Intel Capital came "Mama Intel" if you like [...] so Intel Capital was no more and no less a very capable entity like the other VCs. The bonus point was that there was Intel interest behind it” (I-41)

In accordance with such ascriptions, Intel Capital was consistently identified by our interviewees as being the most influential and - with regard to financial resources, technological expertise, and its ability to shape its supply chain - by far the best endowed and most experienced actor of its kind in the whole industry, which underscores Intel’s signalling practice.

Concerning the resources of domination, we revert to the practice of financing, understood as providing financial resources needed to pursue a technological option - as follows: the process of roadmap gap filling is utilized by Intel in order to allocate financial resources in the form of equity as an allocative resource to suppliers like Media Lario Technology or NaWoTec that develop technological options in line with its own corporate objectives. As a result, Intel is able to exert power and influence in the course of interacting with other organizations while the practice of roadmap gap filling is utilized for the distribution of allocative and authoritative resources. Therefore, European suppliers such as the Italian-based Media Lario Technologies are enabled to pursue aggressively the development of EUV components - and EUV is the next generation lithography technology Intel prefers. Without these investments, the company would simply not be able to pursue these objectives - and, in turn, not be in a position to fill the roadmap gap for Intel and possibly the whole industry. Hereby, authoritative resources are used to exert power insofar as Intel Capital influences decisions about the use of the invested capital by its participation in the firm's supervisory board, as this implies an influence upon the overall strategy of the company. 
When analyzing the practice of roadmap gap filling as a leadership practice, rules of legitimation become evident in the form of providing technological expertise and, thereby, influencing how things happen in the network. We observe this practice when Intel Capital supports the development of its portfolio companies by contributing technological expertise and access to other crucial members of the EUV supply chain. This activity is pursued by providing key personnel and critical know-how as well as legal advice or licenses/patents. This is of vital importance for the development of components in line with required specifications and, thus, enabling the overall supply chain to work efficiently. Apart from this, Intel also trains employees from the companies with regard to social skills and technical expertise. This has an enabling character, as it offers new business and collaboration opportunities. Hereby, members of the supply chain are enticed to cooperate with the Intel Capital-backed suppliers.

\section{Interconnected roadmapping allowing for network manoeuvring}

Having introduced the two practices of roadmapping and roadmap gap filling influenced by and aiming at the network level, we suggest in line with structuration theory that these two practices are closely and recursively interrelated, insofar as they represent social practices that (re)produce the informally enacted leadership position of Intel in both networks. What is more, the interconnectedness of these practices and the set of practices that constitute them is an outcome as well as a means of network manoeuvring in both types of networks, heterarchical and hierarchical. This is illustrated by Intel's diverse attempts to influence the agenda-setting via roadmaps, as well as the interorganizational practice of roadmap gap filling.

Based upon our findings, we derive more general and more specific conclusions (ensuing from the set of practices constituting roadmapping and roadmap gap filling) regarding the interconnection between roadmapping and roadmap gap filling, emerging from and contributing to the (re)production of a heterarchical and a hierarchical network respectively. This can be grasped 
in terms of their mutual interplay over time, as both practices (re)inform each other (cf. again Figure 3). As Intel exerts an innate impact upon the formulation of the industry-wide ITRS, i.e. depending on which technological option or path is likely to be pursued by means of politicking, partnering and consensus-building, it influences the activities, i.e. makes things happen, within SEMATECH as a heterarchical network. As a result, roadmapping within SEMATECH has an influence upon Intel's supply chain, since roadmap gap filling - constituted by signalling, financing and providing technological expertise - is informed by roadmapping, i.e. the ITRS. As illustrated for the case of roadmapping against the backdrop of SEMATECH, we submit that this consensus-based and informally accepted network leadership points to heterarchy-based network manoeuvring, resulting in the following

Proposition 1: Leading de facto a heterarchical network enhances the possibilities for a focal organization to lead a hierarchical network.

Conversely, the same holds true as Intel's roadmap gap filling activities have an impact upon the state of development or even overall success of the technological options preferred by Intel. This in turn strengthens the impact Intel can exert on the ITRS board when it comes to promoting the respective technological options. As illustrated for the case of Intel's roadmap gap filling, we suggest that this specific occurrence of network leadership reflects hierarchy-based network manoeuvring, leading to the following

Proposition 2: Leading a hierarchical network empowers an organization to lead de facto a heterarchical network.

Taken together, both practices revert to the same form of artefact (i.e. a roadmap), albeit there are differences: in their articulation (a consensus document vs. a solely Intel initiated document), timing (long-term oriented vs. rather short-term oriented along the supply chain), deployment (de facto industry wide emanating from SEMATECH vs. oriented along the supply chain), and in particular with regard to the capabilities required (negotiation skills for political manoeuvres vs. 
calculating risks of investments and attracting fellow investors). However, we suggest that propositions 1 and 2 can be combined to develop proposition 3, as both processes, roadmapping and roadmap gap filling, reinform and eventually even reinforce each other recursively, helping Intel to lead different networks effectively over time:

Proposition 3: Hierarchy- and heterarchy-based manoeuvring are likely to mutually reinforce each other if interconnected practices based on a resource relevant for manoeuvring in both network forms is considered meaningful and legitimate.

\section{Implications}

\section{Managerial implications - the practice of roadmapping as a substitute for formally legitimated leadership}

Although this research concentrated upon a single case study in one specific industry, we are able to provide some conclusions that are valuable for managers concerned with managing interorganizational networks in general (cf. Figure 6).

Figure 6 about here

First of all, when it comes to heterarchical network structures, the lack of formally legitimated leadership can be compensated for by leadership practices that are adapted to the specific circumstances. In more detail, it is then important to strive for a factual leadership that is informally accepted, among others, due to the consensus-based nature of the mechanisms. Herein we confirm previous findings of Dyer and colleagues regarding supplier networks where similar mechanisms and partner specific activities have been identified, e.g. providing technical expertise. This may be the case either because others perceive a leadership vacuum or accept the 
factual leadership, e.g. as is the case with Intel, in face of a record of having an innovative reputation or disposing of a renowned venture capital entity that, in collaboration with other partners, is able to develop momentum in favour of certain technological options.

Second, our findings indicate that a company is likely to benefit from reflecting upon its own embeddedness into different network contexts, in particular beyond the immediate single network scope within which it attempts to achieve certain objectives. Relating to previous research on alliance portfolios, we suggest that various phenomena of these wider contexts ought to be taken into consideration, e.g. the formulation and pursuit of objectives formulated within technological roadmaps or other joint activities that are pursued by a wide range of industry participants, not only by those stemming from the focal - in this case heterarchical - network. Another consensus-based phenomenon fostering networking and therefore worth considering might be conferences where actors from the respective industry meet and exchange ideas. In our case, this concerns venues like SPIE conferences. At this convention, all the important actors interested in lithography convene annually and exchange their ideas. Similar to the practice of roadmapping, Intel is able to exert an influence upon the agendas of these conferences. Taken together, we deem it important to take such leadership practices into consideration, as this might help managers to think of leadership as an 'outside-inside'-mechanism as well; that is, influencing artefacts (e.g. the formulation of the ITRS) or arenas (e.g. setting themes in the course of conferences) 'outside' of the network in order to accomplish objectives 'inside' the respective network.

Third, manoeuvring between various networks seems to be worth taking into account as well, in particular between different types of networks. Our research suggests that by means of (partially) aligning Intel's internal supply chain-related roadmap with the industry-wide ITRS, Intel is able to derive benefits from the pursuit of both roadmaps that are intertwined with regard to the company’s activities of manoeuvring an impact between both network forms. We infer this 
from our examination of Intel's various activities to pursue the respective intermediate objectives (milestones) of both roadmaps, which are often interrelated. For instance, objectives formulated in the ITRS appear to inform Intel's internal supply chain-related roadmap, which results in the ensuing roadmap gap filling activities like the support of NaWoTec and Media Lario Technologies with expert training and financial resources. According to our interviewees, filling these gaps, in turn, strengthens Intel's authority within SEMATECH when it comes to formulating the upcoming ITRS. Given this observation, firms ought to attempt to relate their practices in different networks to one another reflexively in order to derive benefits from manoeuvring between these networks.

\section{Theoretical implications - Network manoeuvring as a leadership practice}

Based upon our findings from both types of network that Intel is engaged in, we are able to draw the following theoretical implications - despite the limited generalizeability usually resulting from a single in-depth case study design. As for the differentiation between hierarchy and heterarchy, we refine Hedlund's concept that highlights the often rather loose internal structure of multinational corporations and adapt it to the interorganizational network context. This author views heterarchical forms of organizing as advantageous by comparison to hierarchical forms. This assumption can be traced back to the (potential) benefits of heterarchical structures, i.e. an improved dissemination of knowledge, trust as a form of normative integration among equal partners, a participatory and at the same time consensus-oriented form of finding solutions, and the emergence of temporary leadership due to superior performance or expertise.

Transferring Hedlund's ideas to the realm of interorganizational networks leads to the presumption that leadership in heterarchical networks is - as opposed to formally legitimacybased leadership in hierarchical networks - de facto informal, though based on the social acceptance of one or more actors as leadership-exerting entities by the network members. This acceptance is likely to stem not only from activities inside, but also outside of the focal network. 
Hence it seems worthwhile in studies of network leadership to consider the (possibly also networked) context that the network to be led is embedded in - including other (types of) networks. This is in line with the more structurally oriented discourse on alliance portfolios. However, our findings are more fine-grained, focusing upon practices and micro-practices between two different network forms and over time.

In contrast to hierarchical networks, heterarchical ones are less centralized, i.e. more polycentric in nature. One consequence of this property is that in heterarchical networks decisions and other types of action are more frequently subject to negotiations; as are, for instance, the decisions over SEMATECH budgets that are made on a quid pro quo basis. In addition, while the scope of activities in hierarchical networks usually comprises all networkrelated activities, leadership in or of a heterarchical network is more likely to be distributed among the members. Illustrative evidence supporting this conception in an interorganizational context is also offered by Mortehan ${ }^{33}$, who reports on distributed technological leadership in the information technology industry. This more distributed character of network leadership would have to be taken into account as well when theorizing network leadership in general and network manoeuvring in particular.

Moreover, in contrast to previous studies that concentrate upon leading not only hierarchical, but also single, isolated networks, we broaden the scope of analysis by introducing the very notion of network manoeuvring; that is, we refine approaches geared towards network structures while acknowledging the intertwined nature of enacting leadership in different or even diverse interorganizational networks - manifest in our case around the artefact-based practice of roadmapping concerning two interrelated roadmaps in two types of networks. As a result, research on leadership in interorganizational networks might be worth reconsidering, taking the aspect of manoeuvring intentionally by competent and reflexive actors in and across several networks into account as a 'network-transcending' practice. 


\section{Concluding remarks}

This paper's objective was to elucidate how and under what circumstances Intel is able to exert leadership within SEMATECH as a heterarchical network. The most important insight of this study is that ultimately Intel is only able to lead such a network because it is able to capitalize on its position in another (type of) network: its hierarchical supply chain. We conceptualize this leadership practice as network manoeuvring which is pursued by means of two intertwining leadership practices, roadmapping and roadmap gap filling, both centred on roadmaps as artefacts yet targeted at the heterarchical and the hierarchical network respectively and each consisting of a set of practices that constitute roadmapping and roadmap gap filling respectively. Whereas organizations in hierarchical networks are equally unable to revert to fiat (at least not to the same extent as in intraorganizational constellations), leadership in heterarchical networks is even more dependent upon such alternative opportunities to make things happen based upon resources of domination and in line with rules of signification and legitimation.

Future studies might consider broadening the empirical and methodological scope of our analysis. For instance, apart from analyzing larger empirical samples, it might be intriguing to analyse the participants that influence the ITRS by means of social network analytical tools. If applied for gathering longitudinal data, this might help us to complement our understanding of these leadership practices against the background of more detailed structural information, e.g. with regard to the participating organizations or industry experts in order to illuminate researchrelated interorganizational connections. What is more, roadmapping is a specific, knowledge intensive process in a science-based industry. For example, observing project-based arenas in the film or construction industry or alternatively service-oriented interorganizational networks might result in different forms and patterns of network manoeuvring, fostering our comprehension of the differences between research contexts. 


\section{Appendix}

\section{Method}

A longitudinal in-depth case study approach was chosen in order to comprehend the way Intel Corporation is able to lead a heterarchical network like SEMATECH over time. Employing structuration theory as a constructivist methodology that allows us to capture the social practice of network manoeuvring makes such an approach even more appropriate, as network manoeuvring represents a phenomenon that is in need of further research and is difficult to capture by means of deductive forms of analysis.

\section{Data sources}

The empirical research process started in November 2003 and, as part of an ongoing study of the way in which complex system technologies are extended and created by interorganizational networks, was continued up until October 2010. Apart from an initial data collection from secondary sources in the run-up to the project (e.g. non-scholarly publications), three main sources were utilized for triangulation purposes at regular intervals throughout the course of the project in order to heighten construct validity and avoid respondent bias.

First, we consulted a broad range of archival data in order to reconstruct activities at SEMATECH and in the supply chain. This data included online material (e.g. publicly available brochures, annual reports), material from internal archives or, alternatively, newspaper and journal articles.

Secondly, we conducted 83 semi-structured interviews (on average: 60-90 minutes) on- and offsite with respondents from SEMATECH, its members, and other experts identified as relevant sources for comprehending the activities within SEMATECH and the supply chain and the semiconductor industry more generally (see Table 3). In order to limit biases, we chose 
respondents from various levels and regions, as well as from differing professional backgrounds, namely industry experts, members of political institutions, and fellow researchers.

Table 3 about here

Thirdly, three panels have been held on an annual basis since 2007 in order to deepen our understanding of the semiconductor industry in general (see Table 4). Five experts were selected for the panel, all of whom have different organizational and professional backgrounds and indepth insights into the technology development process. The panel interviews were timed so that they followed the SPIE conference, one of the most important venues for organizational actors relevant to this paper.

Each expert interview - and, in a slightly modified fashion, the panel interviews as well - was oriented towards an interview guideline that consisted of a series of open-ended questions, augmented by follow-up and clarifying questions. The interviews were divided into four central themes that aimed to solicit exploratory information about the way SEMATECH or parts of the supply chain are governed. In particular, the four central themes addressed were: (1) The way interactions within SEMATECH / the supply chain are set up formally, (2) who the dominating actors are, (3) what happens in the case of disagreements, and finally (4) what informal mechanisms can be observed and are utilized to exert an influence within SEMATECH / along the supply chain.

Table 4 about here 
Finally, we conducted follow-up interviews, two seminars and e-mail correspondence with key respondents and discussions with researchers from the fields of organizational sociology and strategic management research, as well as industry respondents as a form of member validation. This allowed us to strengthen our line of reasoning as we integrated their valuable remarks. Moreover, we participated at conference venues and engaged in informal conversations at these occasions to back our impressions or modify them subsequently.

\section{Data analysis}

A qualitative content analysis of the empirical data was performed in order to reconstruct the subjective perspectives of the interviewees toward our study's objective. Although our data analysis did not occur in a linear fashion, it can be roughly divided into the following three stages: in the first stage we collected all data in a case study database to heighten reliability, whereby our analysis is based upon the 'raw data' of 150 pages of field notes, 1,493 pages of interview transcripts, and roughly triple the amount of archival data (including media coverage, both by online journals and trade periodicals via LexisNexis database, English language edition). Written comments and reports on the diverse organizations involved and the practices pursued were compiled and initially systematized in order to obtain an overview. Furthermore, cyclical rereading and protocols by the authors formed the basis for comprehending the way Intel engages in both practices.

Stage two consisted of writing up condensed descriptions of how Intel and the different organizations and networks interact. The resulting detailed descriptions were discussed by the research team and this sensitized us to the way in which Intel manoeuvres in both networks. Throughout the course of this, roadmapping and roadmap gap filling became manifest as the decisive practices concerning both networks. 
In stage three we condensed our empirical data. For this purpose we converted all 'raw data' into PDF-files for a combined analysis in atlas.ti, software for analyzing qualitative data. Figure 7 depicts the emergent data structure, which started with coding at the level of a text unit, defined as a sentence or sequence of sentences conveying a coherent point. Initial coding resulted in 35 first-order categories offered in vivo by informants. At first, some text units were placed in multiple categories to allow for a rich interpretation of data. In what followed we constructed mutually exclusive second-order themes and grouped them hierarchically, which led to the collapse of first-order categories into second-order themes that represent more abstract and researcher-induced interpretations. For instance, we collected all annually edited ITRS documents (complete 'ITRS Editions' have been released each odd-numbered year since 1997 and corrections have been released in 'ITRS Updates' each even-numbered year since 1998) and realized that they emphasize that its output is based upon the "continued consensus of semiconductor experts”. Hence, the technological challenges SEMATECH or even the semiconductor industry per se ought to pursue as most critical are based upon a joint understanding or collective sense-making of where the industry is (supposed to be) heading. Thereafter, the second-order themes were subsumed under the two third-order themes that represent the two practices most relevant for manoeuvring between different networks as an overarching concept.

For construct validity purposes, the analytical themes were reviewed by key informants in the course of re-entering the field parallel to the three stages. By means of conducting focused interviews, ambiguities in our comprehension of roadmapping and roadmap gap filling were resolved. When network manoeuvring - consisting of roadmapping and roadmap gap filling - 
clarified an overarching analytical concept, we compared our results with previous research on leadership in networks and roadmaps to highlight similarities (e.g. the questionable nature of the hard and unbiased facts represented in the roadmap as an artefact) and differences (e.g. congregating), which strengthened the internal validity of our findings and served to match data and theory.

Table 5 about here

Table 5 provides data samples, providing illustrations of the overarching structuration theoretical dimensions of signification, domination and legitimation that the interviewees reverted to in the course of our interviews. Moreover, Table 6 shows examples from different sources, from which we identified and verified the theme of roadmapping. It is worth noting that only those perspectives were integrated that were shared by interviewees with differing types of occupation and hierarchical levels in order to strengthen the internal validity of our claims.

Table 6 about here 


\section{Exhibit 1. Supporting a technological option by means of engaging fellow industry actors}

In 1997 Intel initiated the EUV Limited Liability Company (LLC) to prove the viability of extreme ultraviolet lithography (EUV), one of the post-optical solutions that the whole semiconductor industry and in particular its prime research and development consortium, SEMATECH, were trying to identify. When the members of SEMATECH did not reach a consensus about which technological option ought to be pursued as a next generation lithography by the consortium, Intel - favoring EUV and supporting it with massive financial investments and expertise since 1995 - skillfully persuaded some other SEMATECH members, as well as further important actors like the U.S. Department of Energy related Lawrence and Livermore National Laboratories to join their quest. When the main problematic issues were resolved in the first three years, two more manufacturers, Micron and Infineon, joined the consortium, adding know-how and financial support. A year later in 2001 IBM joined as well, adding further momentum to the effort, although they had been pursuing a competing technological option beforehand as well. These efforts signified that this technological option is likely to be the most successful candidate for a next generation technology, augmenting the prospects for additional resources, which in turn increased industry-wide attention.

When the EUV LLC successfully proved the viability of EUV in 2001, this had enormous implications, improving the legitimacy to pursue this specific technological option and culminating in an even closer collaboration between several SEMATECH members under the auspices of Intel. Intel's decision to invest in the EUV LLC and its announcement that the consortium will have the task of delivering the proof of principle for EUV also influenced many investment decisions made by other SEMATECH and other semiconductor industry members. Thereafter, SEMATECH assessed EUV as one of the main technological options to follow; which is why Intel de facto had massive influence on the development of this technological option.

Table 1: Bipolar continuum of leadership in interorganizational networks.

\begin{tabular}{lll}
\hline \multicolumn{1}{c}{$\begin{array}{c}\text { criteria / type of network } \\
\text { leadership }\end{array}$} & \multicolumn{1}{c}{ hierarchical } & \multicolumn{1}{c}{ heterarchical } \\
\hline $\begin{array}{l}\text { distribution of power } \\
\text { decision making }\end{array}$ & asymmetric & authority-based \\
initiation of leadership related & hierarchically imposed & symmetric \\
activities & consensus-based \\
nature of leadership & formally legitimated & informal, socially accepted \\
degree of formal centralization & high & low \\
scope of centralization & monocentric & polycentric \\
scope of activities & whole range of network-related & $\begin{array}{l}\text { whole or limited range of network- } \\
\text { related activities }\end{array}$ \\
duration & activities & enduring or temporary \\
\hline
\end{tabular}


Table 2: Previous empirically grounded studies on leadership in interorganizational networks.

\begin{tabular}{|c|c|c|c|}
\hline $\begin{array}{c}\text { Conception of leadership with regard to } \\
\text { interorganizational networks }\end{array}$ & Previous research examples & Key insights & Issues that need further exploration \\
\hline Leading / guiding & $\begin{array}{l}\text { Lorenzoni and Baden-Fuller } \\
\text { (1995), Nosella and Petroni } \\
\text { (2007) }\end{array}$ & $\begin{array}{l}\text { Lorenzoni and Baden-Fuller highlight the importance } \\
\text { of creating value as a critical task for the respective } \\
\text { "strategic center"; among others, by means of } \\
\text { sharing information and resources within a single } \\
\text { network. Nosella and Petroni point out that being } \\
\text { able to manage different networks successfully } \\
\text { results in superior performance of the whole system } \\
\text { of networks, whereby the authors also elucidate how } \\
\text { the lead organization can make use of synergies } \\
\text { resulting from the interactions between networks; } \\
\text { conveying a coherent vision and introducing a } \\
\text { cooperative culture supplementing formal } \\
\text { coordination mechanisms are deemed decisive }\end{array}$ & $\begin{array}{l}\text { The way the lead company can benefit from the different } \\
\text { networks in terms of interactions between these different } \\
\text { types of networks remains unexplored in both studies. } \\
\text { Furthermore, the evolution of the network is not captured } \\
\text { on a longitudinal basis. }\end{array}$ \\
\hline Leveraging & $\begin{array}{l}\text { Capaldo (2007), Lorenzoni } \\
\text { and Lipparini (1999) }\end{array}$ & $\begin{array}{l}\text { Leveraging is perceived as a capability residing in an } \\
\text { organization to make use of different network } \\
\text { partners over time }\end{array}$ & $\begin{array}{l}\text { Taking advantage of two (or more) different networks is } \\
\text { not considered while the studies concentrate upon } \\
\text { isolated accounts of different networks }\end{array}$ \\
\hline Orchestrating & $\begin{array}{l}\text { Dhanaraj and Parkhe (2006), } \\
\text { Hinterhuber (2002) }\end{array}$ & $\begin{array}{l}\text { Orchestration is related to a dominant actor or hub } \\
\text { firm that directs the activities of the different } \\
\text { networks }\end{array}$ & $\begin{array}{l}\text { This literature concentrates upon a single network at the } \\
\text { expense of interactions and activities situated between } \\
\text { networks. In addition, in both cases hierarchical networks } \\
\text { are led by a dominant firm }\end{array}$ \\
\hline Mobilising & Hung (2002) & $\begin{array}{l}\text { Mobilising networks is conceived to be a means of } \\
\text { improving the overall performance of the lead firm to } \\
\text { achieve strategic difference; based upon a resource- } \\
\text { dependence perspective, the analysis of three } \\
\text { Taiwanese networks highlights the importance of } \\
\text { considering the networks' embeddedness with } \\
\text { regard to different forms of external relationships }\end{array}$ & $\begin{array}{l}\text { Though different networks are analyzed, they represent } \\
\text { distinctive networks, i.e. each of the three cases is } \\
\text { presented individually. Therefore, in this study as well, it } \\
\text { remains unexplored how a lead firm can take advantage } \\
\text { of participating in two different networks }\end{array}$ \\
\hline Coordinating & $\begin{array}{l}\text { Hoffmann (2005), Huemer } \\
\text { (2006) }\end{array}$ & $\begin{array}{l}\text { Both studies explore the coordination of a network, } \\
\text { whereby in particular with regard to the study of } \\
\text { Hoffmann a more macro approach is adopted, that } \\
\text { is, a portfolio of dyadic ties and alliances is } \\
\text { considered }\end{array}$ & $\begin{array}{l}\text { Interactions between different networks are only } \\
\text { mentioned fleetingly and it remains unclear how a lead } \\
\text { firm can take advantage of being active in different } \\
\text { networks }\end{array}$ \\
\hline Governing & $\begin{array}{l}\text { de Man and Roijakkers } \\
\text { (2009), Hipkin and Naude } \\
\text { (2006), Huxham (2000) }\end{array}$ & $\begin{array}{l}\text { Leadership issues related to governing in this stream } \\
\text { of research are usually associated with the design of } \\
\text { formal contracts between the network partners and } \\
\text { the ensuing risks of such cooperations that stem } \\
\text { from the accompanying inability to avoid all forms of } \\
\text { risk (e.g. opportunism) by means of contractual } \\
\text { obligations }\end{array}$ & $\begin{array}{l}\text { In these studies legal and social control mechanisms are } \\
\text { observed only with regard to specific single networks, but } \\
\text { no interactions between different (forms of) networks are } \\
\text { considered }\end{array}$ \\
\hline
\end{tabular}

Table 3: List of interviews.

Other consortia

Chip manufacturers

Venture capitalist

Senior civil servants

Research laboratories 
Table 4: Composition of the panel.

\begin{tabular}{lll}
\hline \multicolumn{1}{c}{$\begin{array}{c}\text { Panel Participant's } \\
\text { Organization }\end{array}$} & \multicolumn{1}{c}{ Region } & \multicolumn{1}{c}{ Function } \\
\hline AMTC & GER & Senior Executive \\
Intel & USA & Project Leader \\
SEMATECH & USA & Senior Executive \\
SEMATECH & USA & Senior Executive \\
Qimonda & GER & Director Strategic Development
\end{tabular}



EUV subsequently. You can see that very clearly: The number of contributions [at conferences] and the number of people that are working on EUV now increases continuously" (I-16).

Resources of domination

"Intel has felt that EUV is an attractive goal, whereas other companies might have a different agenda. Now, in the case of Intel, just again speaking from the Intel side, what Intel wants is a solution that is cost-effective on the time schedule that it needs [...] But having said that, the champions with in the company then have to pick which directions to put their resources in and that then dictates which direction each organization will push [...] I think $[\ldots]$ the roadmap exercises [...] first and foremost, it helps people within organizations to align their resources to be able to tackle these problems. So if you've got a champion within the company and by making use of the roadmap [...] they can help get the management support they need" (I-32).

Rules of legitimation

"all [important actors] are coming and they present their status and all the people interested in EUV are there sitting and you can ask questions and it is all open, a more or less public environment, in these meetings; I've been going to them in quite early years, really, [they] are quite open. It is not just everyone taking notes and not saying anything, so I think these meetings do help bring all the players together and help build some consensus and give some direction to these key value chain infrastructure developers" (I-68).

"The fact that we as IC [Intel Capital] cooperate with the firm, or rather, invest into this firm offers a large variety of opportunities for this firm - and for Intel as well. The fact that we invest into this firm is an important proof point for other investors, and the market per se [..] and if the firm is successful, Intel will profit from that investment in turn" (I-55).

Resources of domination

"a novel fab [(that is, factory) ...] costs about three billion dollar and more. That's an enormous asset and a lot of capital will be bound that needs to amortize. And, therefore, we work on this issue with our whole supply chain over various steps of the whole chain" (I-53).

Rules of legitimation $\quad$ "The value of Intel was also very great, because they [Intel] positioned themselves as key account and thereby they gave legitimacy to the firm they invested in" (I-65) 
Archival data

Interview data

Roadmap Gap Filling

"Intel has become synonymous with the word leadership. For more than a quarter century, the company has been the leader in the very high tech realm of microprocessor technologies with the marketplace responding in like manner with ever increasing market shares. Today, people know just as much (or more) about Moore's Law, named after Intel's cofounder Gordon Moore, as they know about the laws ascribed to Newton, Einstein, or even Murphy. (Intel celebrated the 40th Anniversary of Moore's Law this past April.) For much of those past 25 years Intel's technology leadership followed a technically complex, but relatively predictable path as each new generation of microprocessor was designed and fabricated on the next iterative design step in the International Technology Roadmap for Semiconductors. And while that Roadmap continues to be supported with guidelines out to the year 2018, the overall rules are changing as the power and heat generated increases in each new generation of these densely packed devices and it surpasses the ability to keep it cool" (Studt 2005)

"Intel addresses [new technologies often] to the American market at first. If they realize that this [technology] does not function in America, then they make a tremendous effort, then they take a look 'outside', then they invite others [...] And then Intel says 'Well, that is interesting' and then they go there [to SEMATECH] and announce that they would like to have this [technology and] then SEMATECH will finance this or finance it partially" (I-45)

Archival data

"Whether it's an investment in a tiny wireless start-up or a $\$ 2.6$ billion memory chip maker, Intel Corp. follows the same strategy: pump money into companies whose products will ensure future demand for the Santa Clara, Calif., semiconductor maker's own chips. The latest example of this push was unveiled late Wednesday, Sept. 25 , when the world's largest chipmaker announced a $\$ 450$ million investment in dynamic random access memory chipmaker Micron Technology Inc. Along with a 5.3\% stake in Boise, Idaho based Micron, Intel gets a pledge by Micron to boost its production of "DDR2," a faster memory chip technology, and increase its ability to make $300 \mathrm{~mm}$ semiconductor wafers. "We don't want any individual companies to be the limiting factor in our ability to supply our customers," said Intel spokesman Chuck Mulloy. "Our rationale is to ensure that memory makers' roadmaps are in alignment with ours." [...] Two divisions of Intel negotiated the deal with Micron: Intel Capital, the chipmaker's investment arm, and the company's technology manufacturing group, led by Intel vice president Gidu Shroff' (de Senerpont Domis 2003)

Interview data

"I would say that we really start to look at [the technological development] from the start of the supply chain. As for EUVL, for instance, the beginning is Media Lario; well actualy it's not really at the beginning. Media Lario is - when I take a look at the whole supply chain of such a product - more of a stepper with all the subsystems that need to fit in there. Then Media Lario is actually more in the middle. As for the EUV light sources, we were also stepper with all the subsystems that need to fit in there. Then Media Lario is actually more in the middle. As for the EUV light sources, we were also
investing into a firm called XTREME. That's been a joint venture of USIO and JENOPTIK, and we made investments in the USA. In these cases we investing into a firm called XTREME. That's been a joint venture of USIO and JENOPTIK, and we made investments in the USA. In these cases we
really consider the whole supply chain from the beginning to the end and ponder where it is worthwhile to consider VC [venture capital] investments, speeding up the development and also to get other partners into our boat. Media Lario - with what they are doing as a subsystem suppier - they are actually situated between the stepper and the [light] source and eventually all [...] things need to fit together in order to make it a useful product for Intel or others. That's what we mean by roadmap gap" (I-54) 
Figure 1: The duality of structure (Giddens 1984, 29).

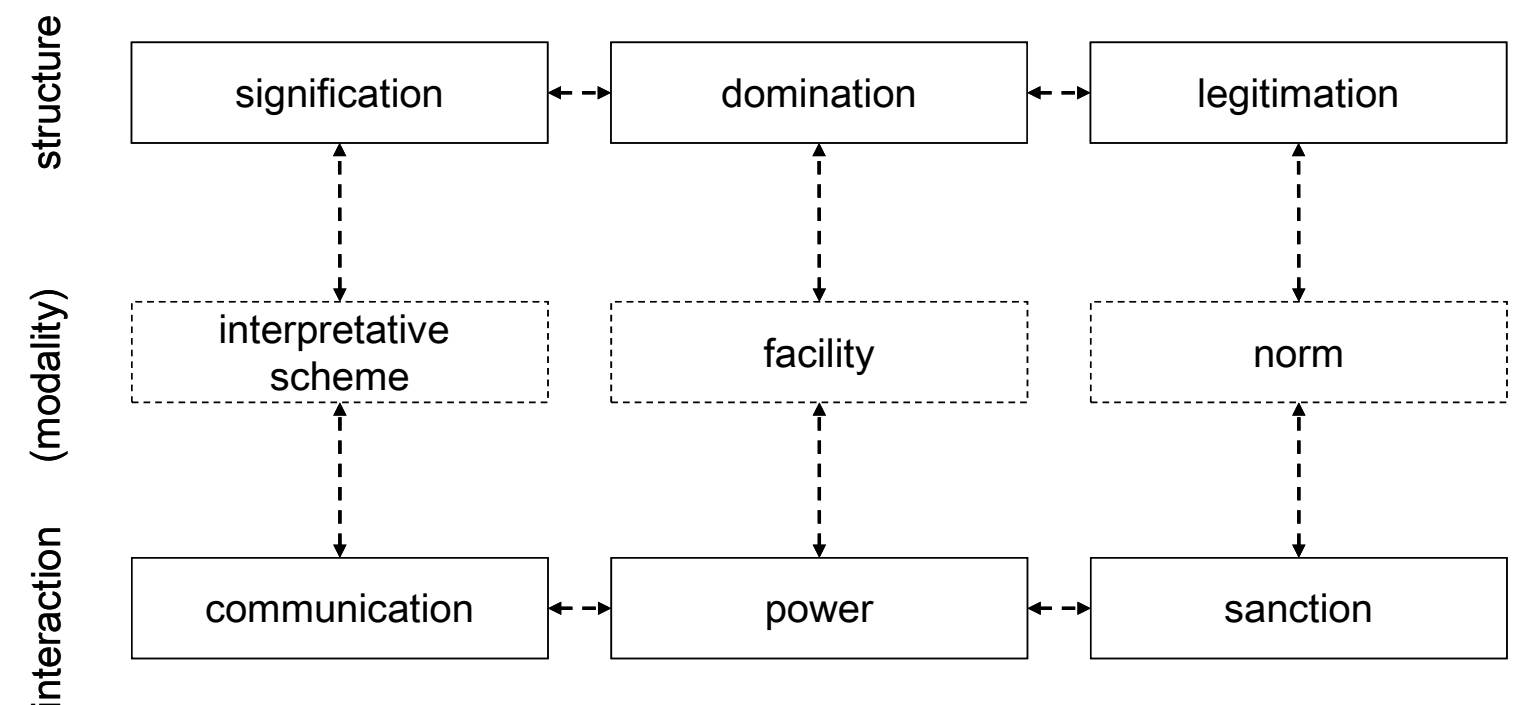

Figure 2: Parts of Intel's EUVL technology supply chain.

\section{Intel}

Headquarters: Santa Clara/California (USA)

Main products: Microprocessor

$R G F^{*}$ activities: Financing of roadmap gaps

identified by the ITRS and

its own roadmap by means

of Intel Capital

\section{Media Lario Technologies}

Headquarters: Bosisio Parini (ITA)

Main products: Optical EUVL components

RGF activities: Acquisition of venture capital

for the development of EUVL

instruments from Intel Capital

and other venture capitalists

\section{NaWoTec}

Headquarters: Rossdorf (GER)

Main products: Photo mask repair tools

RGF activities: Acquisition of venture capital

for its tools from - first and

foremost - Intel Capital,

Wellington Partners and

Target Partners. 
Figure 3: Intel as a network manoeuvring in different networks by leveraging its impact on the intertwined roadmaps (n.b.: P1-P3 represent the propositions we set out in depth in the remainder of the paper).

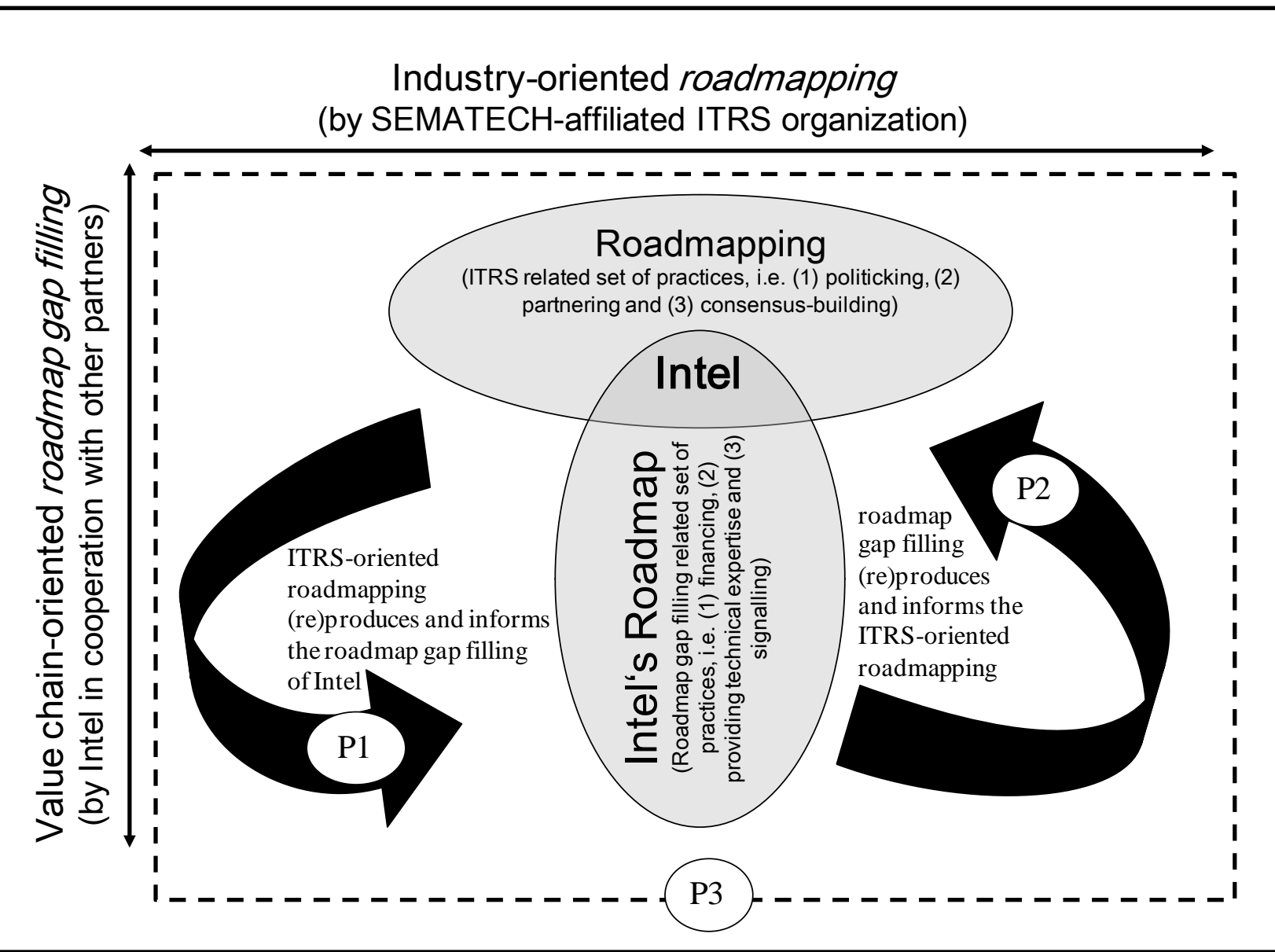

Figure 4: Roadmapping as a leadership practice.

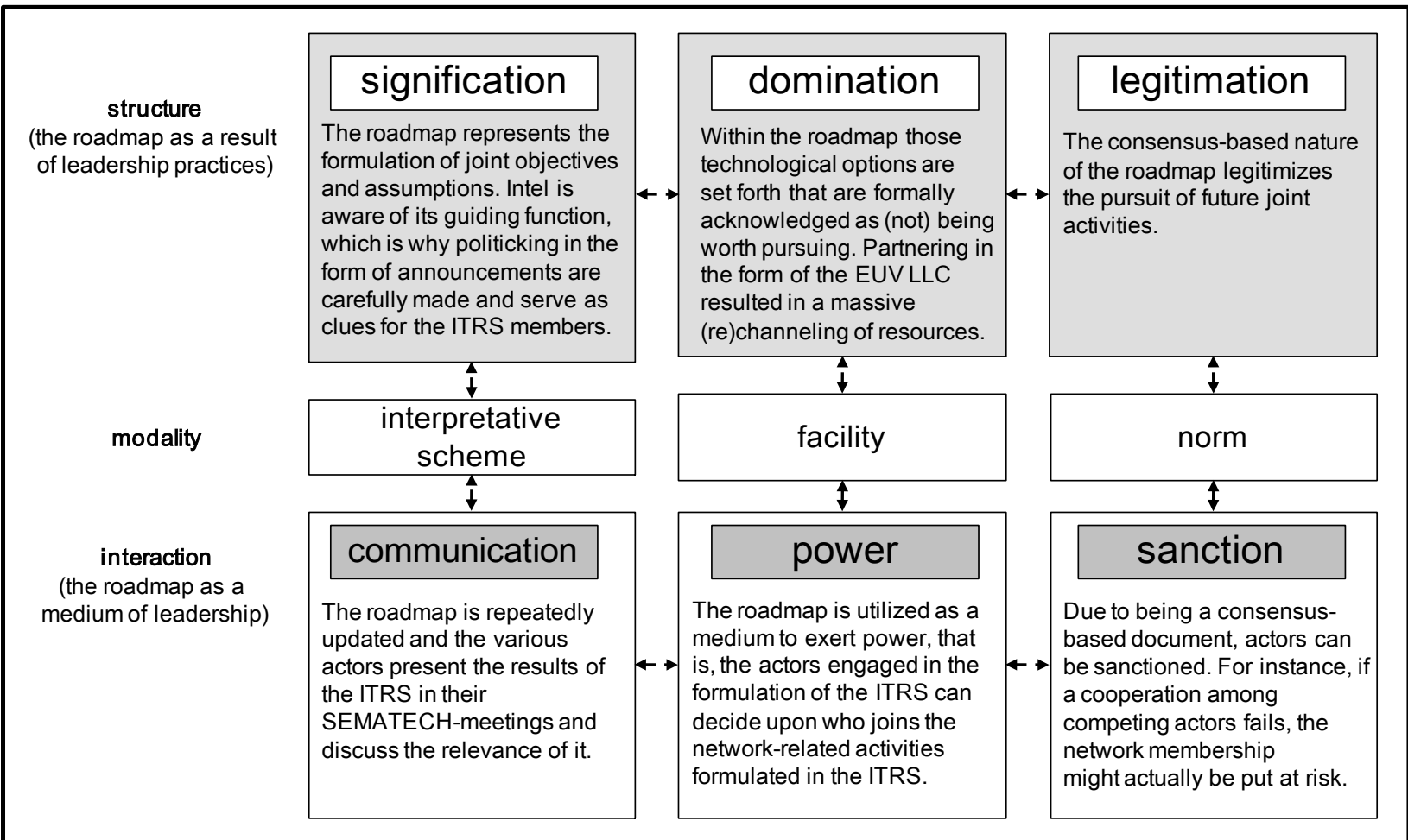


Figure 5: Roadmap gap filling as a leadership practice.

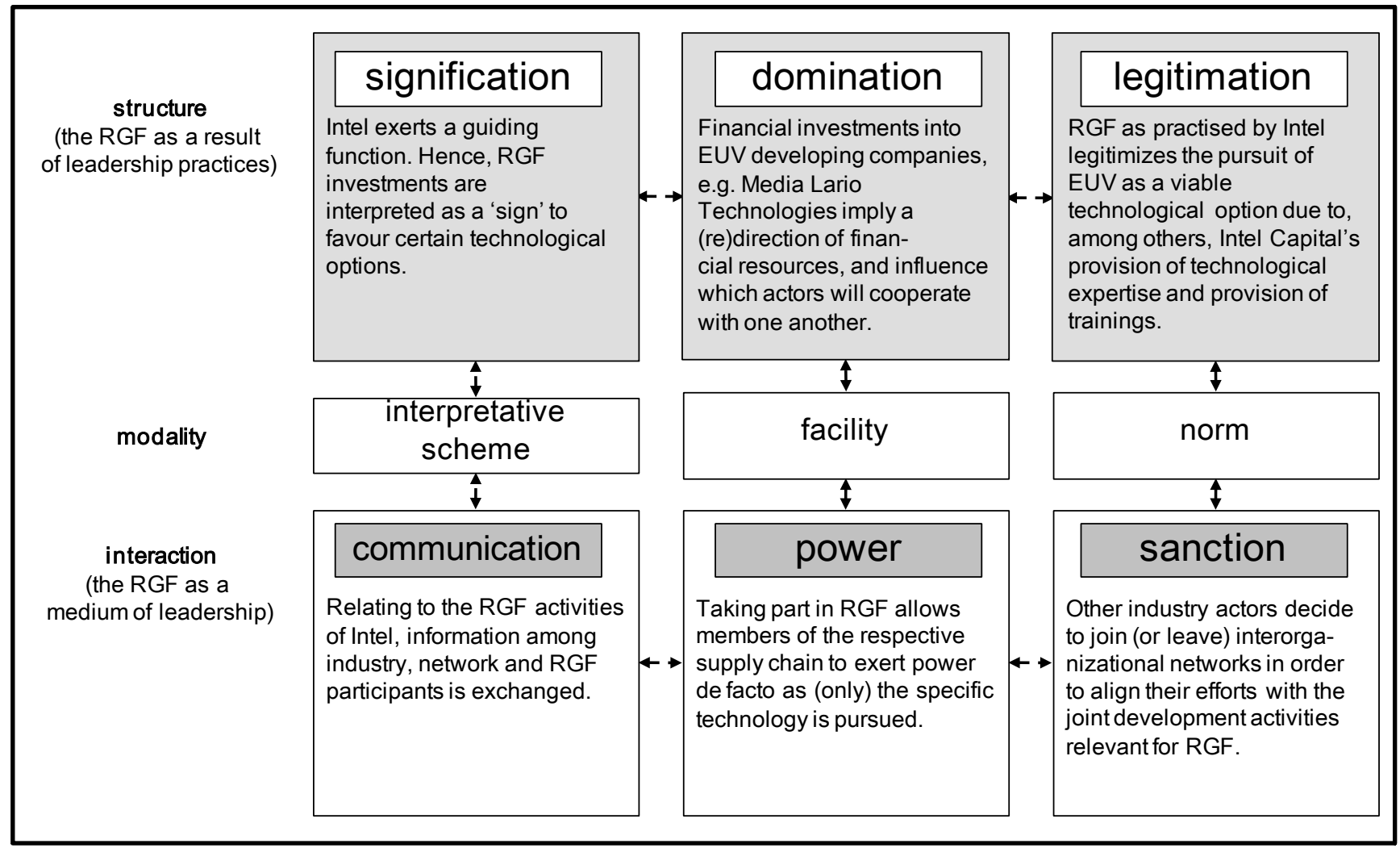

Figure 6: Managerial implications of this study.

\section{Managerial implications}

- Adopt a perspective that considers networks sep erately instead of assuming solely a 'macro'-oriented network p ortfolio approach, while at the same time broaden the scope of analysis beyond single networks in order to allow for network manoeuvering

- Establish an awareness of outside-inside mechanisms particularly relevant for heterarchical networks, i.e. factors that might influence the activities in a heterarchical network to identify the potential phenomena or objects relevant for network manouevering

- Analyse your organization's embeddedness into other different interorganizational network engagements; in particular pay attention to different forms of interorganizational networks

- Target arenas where information can be disseminated that is likely to influence relevant audiences, e.g. Conferences, in order to influence consensus-based mechanisms prevailing in heterarchical networks 
Figure 7: Emergent data structure.

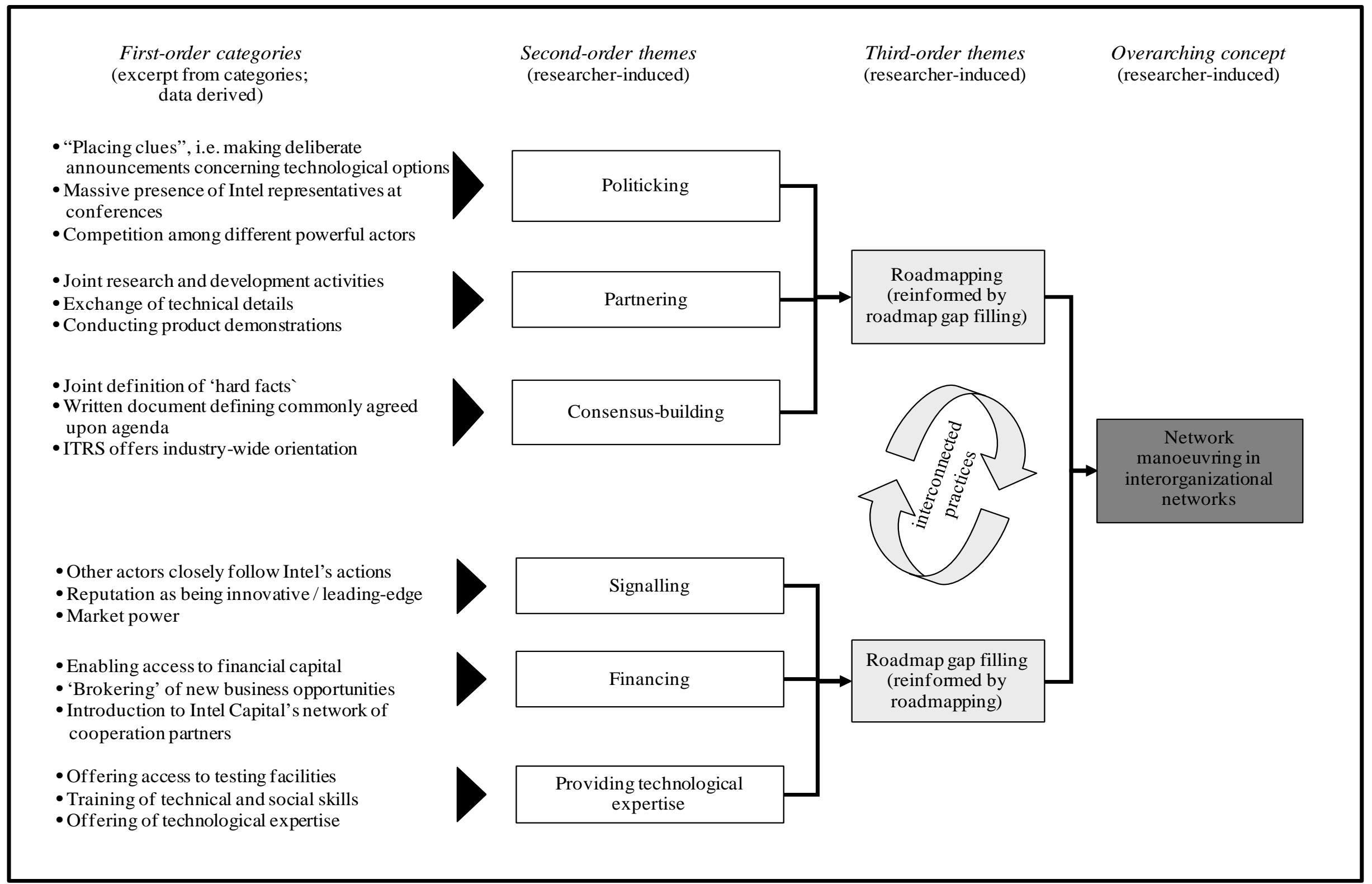


${ }^{1}$ J. C. Jarillo, On strategic networks, Strategic Management Journal 9(1), 31-41 (1988); G. Grabher and W. W. Powell, Networks, Elgar, Cheltenham, UK, Northampton, MA, USA (2004); W. W. Powell, Neither market nor hierarchy: Network forms of organization, Research in Organizational Behavior 12, 295-336 (1990); R. Gulati, Alliances and networks, Strategic Management Journal 19(4), 293-317 (1998); For an overview: R. Gulati, N. Nohria, and A. Zaheer, Strategic networks, Strategic Management Journal 21(3), 203-215 (2000); B. Cassiman, M. C. Di Guardo and G. Valentini, Organising R\&D projects to profit from innovation: Insights from co-opetition, Long Range Planning 42(2), 216-233 (2009); S.-C. Hung, Mobilising networks to achieve strategic difference, Long Range Planning 35(6), 591-613 (2002); W. W. Powell, K. W. Koput, and L. Smith-Doerr, Interorganizational collaboration and the locus of innovation: Networks of learning in biotechnology, Administrative Science Quarterly 41(1), 116-145 (1996).

${ }^{2}$ R. Gulati, N. Nohria and A. Zaheer, Strategic networks, Strategic Management Journal 21: 203-215 (2000); K.H. Heimeriks and G. M. Duysters, Alliance Capability as a Mediator Between Experience and Alliance Performance: An Empirical Investigation into the Alliance Capability Development Process, Journal of Management Studies 44(1): 25-49 (2007); W. H. Hoffmann, Strategies for Managing a Portfolio of Alliances, Strategic Management Journal 28: 827-856 (2007); P. Kale, J. Dyer and H. Singh, Alliance capability, stock market response, and long term alliance success: The role of the alliance function, Strategic Management Journal 23(8): 747-767 (2002); P. Kale and H. Singh, Building Firm Capabilities Through Learning: The Role of the Alliance Learning Process in Alliance Capability and Firm-Level Alliance Success, Strategic Management Journal 28: 981-1000 (2007).

${ }^{3}$ H.G. Barkema and M. Schijven, How Do Firms Learn to Make Acquisitions? A Review of Past Research and an Agenda for the Future, Journal of Management 34(3): 594-634 (2008); J. H. Dyer, Does Governance Matter? Keiretsu Alliances and Asset Specifity as Sources of Japanese Competitive Advantage, Organization Science 7(6): 649-666 (1996).; J. H. Dyer, Collaborative Advantage: Winning Through Extended Enterprise Supplier Networks, Oxford University Press, Oxford (2000); J. H. Dyer and N.W. Hatch, Relation-specific Capabilities and Barriers to Knowledge Transfers: Creating Advantage Through Network Relationships, Strategic Management Journal 27: 701-719 (2006); J. H. Dyer and K. Nobeoka, Creating and managing a high-performance knowledge-sharing network: The Toyota case, Strategic Management Journal 21: 345-367 (2000); B. Gomes-Casseres, The Alliance revolution. The New Shape of Business Rivalry, Harvard University Press, Cambridge 
(1997); Perrons, R. K. 2009. The open kimono: How Intel balances trust and power to maintain platform leadership. Research Policy, 38(8): 1300-1312.

${ }^{4}$ See, in particular, C. Huxham and S. Vangen, Leadership in the shaping and implementation of collaboration agendas: how things happen in a (not quite) joined-up world, Academy of Management Journal 43(6), 1159-1175 (2000); cf. also C. Huxham and S. Vangen, Managing to Collaborate. The theory and practice of collaborative advantage, Routledge, London (2005) and C. Huxham, The challenge of collaborative governance, Public Management 2(3), 337-357 (2000)..

${ }^{5}$ G. Lorenzoni and C. Baden-Fuller, Creating a strategic center to manage a web of partners, California Management Review 37(3), 146-163 (1995); C. Dhanaraj and A. Parkhe, Orchestrating innovation networks, Academy of Management Review 31(3): 659-669 (2006); R. Häcki and J. Lighton, The future of the networked company, McKinsey Quarterly 37(3), 26-39 (2001); A. Nosella and G. Petroni, Multiple network leadership as a strategic asset: The Carlo Gavazzi space case, Long Range Planning 40, 178-201 (2007). K. H. Heimeriks, E. Klijn and J. J. Reuer, Building capabilities for alliance portfolios, Long Range Planning 42, 96-114 (2009).

${ }^{6}$ Cf. for a recent overview U. Wassmer, Alliance portfolios: A review and research agenda, Journal of Management 36(1): 141-171 (2010).

${ }^{7}$ K. Eisenhardt and J. Martin, Dynamic Capabilities: What are They?, Strategic Management Journal 21(10/11): 1105-1122 (2000) and again Wassmer (2010) as well as Barkema and Schijven (2008).

${ }^{8}$ Accounts on open source software related issues are offered by Y. Benkler, The Wealth of Networks. How Social Production Transforms Markets and Freedom, Yale University Press, New Haven and London (2006); K. Crowston and J. Howison, Hierarchy and centralization in free and open source software team communications, Knowledge, Technology \& Policy 18(4), $65-85$ (2006); with regard to multinational corporations see G. Hedlund, The hypermodern MNC: A heterarchy?, Human Resource Management 25(1), 9-36 (1986); G. Hedlund and D. Rolander, Action in heterarchies - New approaches to managing the MNC, in C. A. Bartlett, C. A. Doz, Y. Doz, and G. Hedlund (eds.), Managing the global firm, Routledge, London, 15-46 (1990); C. Lechner and M. Kreutzer, Coordinating growth initiatives in multi-unit firms, Long Range Planning 43(1), 6-32 (2010); With regard to public settings see again Huxham and Vangen (2000) who elaborate upon how leadership is enacted by “making things powerfully happen”; A. de Man and N. Roijakkers, Alliance governance: Balancing control and trust in dealing with risk, Long Range Planning 42, 75-95 (2009); I. Hipkin and P. Naudé, Developing effective alliance partnerships: Lessons from a case study, Long Range Planning 39(1), 51-69 (2006); W. H. Hoffmann, How to manage a portfolio of alliances, Long Range Planning 38(2), 121-143 (2005); C. Huxham and S. Vangen, Ambiguity, complexity and dynamics in 
the membership of collaboration, Human Relations 53(6), 771-806 (2000); C. W. Stern, The deconstruction of value chains, (2006), Available from: http://www.bcg.com/impact_expertise/publications/files/Eng372TheDeconstruction.pdf; cf. also C. Huxham and S. Vangen, Leadership in the shaping and implementation of collaboration agendas: how things happen in a (not quite) joined-up world, Academy of Management Journal 43(6), 1159-1175 (2000); C. Y.-Y. Lin and J. Zhang, Changing structures of SME networks: Lessons from the publishing industry in Taiwan, Long Range Planning 38(2), 145-162 (2005). In addition, with regard to practice based theorizing in line with structuration theory we follow Jarzabkowski: P. Jarzabkowski, Shaping strategy as a structuration process, Academy of Management Journal 51(4), 621-650 (2008).

${ }^{9}$ L. Araujo and C. Brito, Agency and constitutional ordering in networks. A case study of the port wine industry, International Studies of Management and Organization 27(4), 22-46 (1997-98); L. D. Browning, J. M. Beyer and J. C. Shetler, Building cooperation in a competitive industry: Sematech and the semiconductor industry, Academy of Management Journal 38(1), 113-151 (1995).

${ }^{10}$ A. Giddens, The Constitution of Society: Outline of the Theory of Structuration, Polity Press, Cambridge (1984). J. Sydow and A. Windeler, Knowledge, trust, and control. Managing tensions and contradictions in a regional network of service firms, International Studies of Management \& Organization 33, 69-99 (2003). For an overview of the usage of this theory for understanding strategic management see A. Pozzebon, The influence of a structurationist view on strategic management research, Journal of Management Studies 41(2), 247-272 (2004).

${ }^{11}$ In addition to the literature cited above regarding network related issues in open source software development and multinational corporations, relevant discussions for this study of leadership in alliances and joint ventures has been discussed under the heading of network or alliance evolution, e.g. L. Rosenkopf, A. Metiu, and V. P. George, From the bottom up? Technical committee sctivity and allicance formation, Administrative Science Quarterly 46, 748-772 (2001).

12 J. Sydow and A. Windeler (2003) as cited above.

${ }^{13}$ C.M. Harland, Supply chain management: Relationships, chains and networks, British Journal of Management 7, 63-80 (1996); S. Cooray and J. Ratnatunga, Buyer-supplier relationships: A case study of a Japanese and western alliance, Long Range Planning 34, 727-740 (2001).

${ }^{14}$ M. J. Dollinger, The evolution of collective strategies in fragmented industries, Academy of Management Review 15(2), 266-285 (1990); J. H. Dyer and H. Singh, The relational view: Cooperative strategy and sources of interorganizational competitive advantage, Academy of Management Review 23(4), 660-679 (1998). 
${ }^{15}$ Cf. Rosenkopf et al. (2001) as cited above; L. Rosenkopf and M. L. Tushman, The coevolution of community networks and technology: Lessons from the flight simulation industry, Industrial and Corporate Change 7(2), 311-346 (1998); M. L. Tushman and L. Rosenkopf, Organizational determinants of technological change: Toward a sociology of technological evolution, Research in Organizational Behavior 14, 311-347 (1992).

${ }^{16}$ Y. L. Doz, P. M. Olk, and P. S. Ring, Formation processes of R\&D consortia: Which path to take? Where does it lead?, Strategic Management Journal 21(3), 239-266 (2000); P. S. Ring, Y. L. Doz, and P. M. Olk, Managing formation processes in R\&D consortia, California Management Review 47(4), 137-156 (2005).

${ }^{17}$ C. Boari and A. Lipparini, Networks within industrial districts: Organising knowledge creation and transfer by means of moderate hierarchies, Journal of Management and Governance 3(4), 339-360 (1999); L. Huemer, Supply management: Value creation, coordination and positioning in supply relationships, Long Range Planning 39(2), 133-153 (2006); M. Lazerson and G. Lorenzoni, Resisting organizational inertia: The evolution of industrial districts, Journal of Management and Governance 3(4), 361-377 (1999); A. Saxenian, Regional networks and the resurgence of Silicon Valley, California Management Review 33(1), 89-112 (1990); S. Brusco, The Emilian model: Productive decentralization and social integration, Cambridge Journal of Economics 6, 167-184 (1982); in this connection, we primarily revert to the notions of Provan and colleagues with regard to 'whole networks' as well as Lizzarini's understanding of 'explicit constellations': K. G. Provan, A. Fish, and J. Sydow, Interorganizational networks at the network level: A review of the empirical literature on whole networks, Journal of Management 33(3), 479-516 (2007); S. G. Lazzarini, The impact of membership in competing alliance constellations: Evidence on the operational performance of global airlines, Strategic Management Journal 28(4), 345-367 (2007).

\section{${ }^{18}$ A. Gawer and M. A. Cusumano, Platform leadership: How Intel, Microsoft, and Cisco drive} industry innovation, Harvard Business School Press, Boston, MA (2002); A. Hinterhuber, Value chain orchestration in action and the case of the global agrochemical industry, Long Range Planning 35(6), 615-635 (2002); C. Jones, W. S. Hesterly and S. P. Borgatti, A general theory of network governance: Exchange conditions and social mechanism, Academy of Management Review 22(4), 911-945 (1997).

${ }^{19}$ As we will set forth in more detail in the literature review, our conception of maneuvering resembles existing notions of 'leveraging’ as set forth by Lorenzoni and Lipparini (1999) and Capaldo (2007); A. Capaldo, Network structure and innovation: The leveraging of a dual network as a distinctive relational capability, Strategic Management Journal 28(6), 585-608 (2007); G. Lorenzoni and A. Lipparini, The leveraging of interfirm relationships as a distinctive organizational capability: A 
longitudinal study, Strategic Management Journal 20(4), 317-338 (1999); cf. also M. Kodama, Boundaries innovation and knowledge integration in the Japanese firm, Long Range Planning 42(4), 463-494 (2009). What is more, parallels can be drawn to Burt's conception of structural holes; R. S. Burt, Structural Holes: The Social Structure of Competition, Harvard University Press, Cambridge/Massachusetts (1992). This appears in this regard intuitively appealing to enrich our understanding concerning the structural characteristics of such networks and leadership therein as well as between them. However, our approach differs from this conception as Burt's approach focuses upon sparse networks of a transactional type rather than on dense collaborative relationships and does not differentiate between network forms; cf. in this regard the criticism by M. Emirbayer and J. Goodwin, Network Analysis, Culture and the Problems of Agency, American Journal of Sociology 99(6), 14111454 (1994); D. Knoke, Political Networks. The Structural Perspective, Cambridge University Press, Cambridge (1990). G. Walker, B. Kogut and W. Shan, Social Capital, Structural Holes and the Formation of an Industry Network, Organization Science 8(2): 109-125 (1997). As a result, Burt’s perspective informed by the rational choice approach would not be able to take fully into account Intel's engagement within SEMATECH, as membership fees need to be paid while at the same time the results of the network are made publicly to all industry actors. Relatedly, historically imprinted aspects of how cooperative relationships within SEMATECH evolved over time (Browning et al. 1995) do not merry with a lens geared towards short term transactions, which is why we submit that SEMATECH members represent reflexive and competent actors as they value long-term perspectives over short-term gains. In addition no differentiation is made between forms of networks, which is why the notion of manoeuvring refines Burt's notion insofar as it specifies brokering concerning different network forms and adopts a practice oriented perspective geared towards mutually reinforming practices.

20 J. Bamford and D. Ernst, Managing an alliance portfolio, McKinsey Quarterly 3, 29-39 (2002); D. Lavie, Alliance portfolios and firm performance: A study of value creation and appropriation in the U.S. software industry, Strategic Management Journal 28(12), 1187-1212 (2007); G. Padula, Enhancing the innovation performance of firms by balancing cohesiveness and bridging ties, Long Range Planning 41(4), 395-419 (2008).

${ }^{21}$ M. A. Cusumano, Y. Mylonadis, and R. S. Rosenbloom, Strategic maneuvering and mass-market dynamics: The triumph of VHS over Beta, Business History Review 66(1), 51-94 (1992); A.

Fiegenbaum, H. Thomas and M. Tang, Linking hypercompetition and strategic group theories: Strategic maneuvering in the US insurance industry, Managerial and Decision Economics 22(4-5), 265-279 (2001). 
22 J. Denis, L. Lamothe and A. Langley, The dynamics of collective leadership and strategic change in pluralistic organizations, Academy of Management Journal 44(4), 809-837 (2001); P. Kenis and K. Provan, The control of public networks, International Public Management Journal 9(3), 227-247 (2006); J. D. Orton and K. E. Weick, Loosely coupled systems: A reconceptualization, Academy of Management Review 15(2), 203-223 (1990).

${ }^{23}$ S. R. Barley and P. S. Tolbert, Institutionalization and Structuration: Studying the Links between Action and Institution, Organization Studies 18(1), 93-117 (1997) and cf. again Jarzabkowski (2008).

${ }^{24}$ K. Dittrich, G. Duysters, and A. de Man, Strategic repositioning by means of alliance networks: The case of IBM, Research Policy 36(10), 1496-1511 (2007); cf. also again Hung (2002). With regard to research on SEMATECH we consulted in particular the following sources: Browning et al. (1995), L. D. Browning and J. C. Shetler, Sematech: Saving the U.S. semiconductor industry, A\&M University Press, College Station, TX (2000); R. M. Ham, G. Linden, and M. M. Appleyard, The evolving role of semiconductor consortia in the Unites States and Japan, California Management Review 41(1), 137163 (1998); SEMATECH, SEMATECH: Accelerating the Next Technology Revolution (2008), Available from: http://www.sematech.org/. Moreover, insights in the semiconductor industry were obtained primarily from. S. Grief, D. E. Williams and T. J. Corra, Who's afraid of the big bad exchange? A primer for suppliers (2001), Available from:

www.bcg.com/impact_expertise/publications/files/

Whos_Afraid_of_the_Big_Bad_Exchange_Feb_01_OFA.pdf; S. Heck and D. Pinner, Creating value in the semiconductor industry, McKinsey \& Company, San Francisco (2007); R. N. Langlois and W. E. Steinmueller, The evolution of competitive advantage in the worldwide semiconductor industry 1947-1966, in D. C. Mowery and R. R. Nelson (eds.), Sources of industrial leadership - Studies of seven industries, Cambridge University Press, Cambridge, 19-78 (1999).

${ }^{25}$ D. Manners, US proposes son of Sematech (2008), Available from: http://www.electronicsweekly.com/Articles/2008/12/19/45182/us-proposes-son-of-sematech.htm. ${ }^{26}$ iSuppli, Competitive landscaping tool 2008 (2008), Available from: http://www.isuppli.com/Abstract/ABSTRACT\%20\%20Competitive\%20Landscaping\%20Tool\%20200 8.pdf; P. Zerbib, J. Holemans, S. Galal, J. Sinha, and T. Wallach, Managing innovation through market discontinuity, Insights (Booz Allen \& Hamilton) 7(3), 2-8 (2001).

${ }^{27}$ General Accounting Office 1992. SEMATECH's Technological Progress and Proposed R\&D Program. Washington, D.C.: General Accounting Office; SEMATECH, 2008 - A year in review. Collaborate. Innovate. Discover (2009), Available from:

http://www.sematech.org/corporate/annual/annual08.pdf. 
${ }^{28}$ Apart from Yin’s account on case study research (R. K. Yin, Case Study Research, Sage, Thousand Oaks et al. (2009)) we oriented our research towards the approaches offered by the following literature: O. J. Borch and M. B. Arthur, Strategic networks among small firms: Implications for strategy research methodology, Journal of Management Studies 32(4), 419-441 (1995); Y. S. Lincoln and E. G. Guba, Naturalistic inquiry, Sage, Beverly Hills et al. (1985). A. C. Edmondson and S. E. McManus, Methodological fit in management field research, Academy of Management Review 32(4), 1155-1179 (2007).

${ }^{29}$ Here and in the following: ITRS, The international technology roadmap for semiconductors (2008), Available from: http://public.itrs.net/home.html; R. R. Schaller, Technological innovation in the semiconductor industry: A case study of the international technology roadmap for semiconductors, Ph.D. Dissertation, George Mason University, Fairfax (2004), Available from:

http://www.xecu.net/schaller/schaller_dissertation_2004.pdf.

${ }^{30}$ M. Radnor and D. R. Probert, Viewing the future, Research Technology Management 47(2), 25-26 (2004).

${ }^{31}$ ITRS, The international technology roadmap for semiconductors (2008), Available from: http://www.itrs.net/about.html.

${ }^{32}$ G. E. Moore, Cramming more components onto integrated circuits, Electronics 38(8), 114-117 (1965); Intel, It's not just what we make. It's what we make possible. 2008 Annual Report (2009), Available from: www.intc.com/intelAR2008/common/pdfs/Intel_2008_Annual_Report.pdf.

33 O. Mortehan, The role of firms' collaborative agreements in the information technology industry transformation, Technology Analysis \& Strategic Management 16(1), 53-71 (2004). 